\title{
Consumer Acceptance and Use of Information Technology: A Meta-Analytic Evaluation of UTAUT2
}

\author{
Kuttimani Tamilmani ${ }^{1}$ - Nripendra P. Rana ${ }^{1}$ - Yogesh K. Dwivedi ${ }^{2}$ \\ Published online: 30 April 2020 \\ (C) The Author(s) 2020
}

\begin{abstract}
Despite being regarded as the most comprehensive theory in understanding individual technology adoption - UTAUT2 theory with growing number of citations and impetus beyond IS domain face strong criticism on usage of the model in its entirety. This study located UTAUT2 based empirical studies in the Scopus and Web of Science bibliographic database through citied reference search in order to evaluate appropriate usage of UTAUT2 constructs. The meta-analysis results spanning across 60 studies with more than 122,000 cumulative observations found $\mathrm{BI} \rightarrow \mathrm{UB}$ as the strongest path with all significant values. $\mathrm{PE} \rightarrow \mathrm{BI}$ emerged as the most utilized path with most significant values underscoring the emphasis placed by consumers on utilitarian value. Meanwhile, with most non-significant path values the future usage of $\mathrm{EE} \rightarrow \mathrm{BI}$ path is been cautioned and questioned. Finally, trust, personal innovativeness, perceived risk, attitude, and self-efficacy were found as the five topmost UTAUT2 extensions.
\end{abstract}

Keywords Meta-analysis $\cdot$ UTAUT2 $\cdot$ Citation analysis $\cdot$ Consumer acceptance $\cdot$ Information technology

\section{Introduction}

In recent decades, Information Technology (IT) has stretched beyond the organisational boundary to the hands of consumers primarily driven by mobile phones penetration across the globe. Mobile technologies comprising 5 billion unique mobile subscribes emerged as the largest form of consumer technology worldwide in 2017, connecting two third of global population to Information and Communication Technology (ICT) (Gsmaintelligence 2017). Despite the scale of ICT, understanding "why" individuals embrace these technologies and "why not" has been continuous concern for research and practice. This highlights the depiction of individual information systems

Nripendra P. Rana

nrananp@gmail.com

Kuttimani Tamilmani

kuttimani.tamilmani@gmail.com

Yogesh K. Dwivedi

ykdwivedi@gmail.com

1 School of Management, University of Bradford, Bradford BD7 1DP, UK

2 Emerging Markets Research Centre (EMaRC), School of Management, Swansea University Bay Campus, Fabian Way, Swansea SA1 8EN, UK
(IS) adoption research as one of the mature research stream in the contemporary IS research arena (Venkatesh et al. 2007; Williams et al. 2009). In order to explain individual IS/IT adoption and use, researchers over these decades have proposed plethora of competing theories and models. This includes popular theories such as: Theory of Reasoned Action (TRA), the Technology Acceptance Model (TAM), theory of planned behaviour (TPB), Diffusion of Innovation (DoI) theory, and Model of Personal Computer Utilization (MPCU) to name a few. Researchers have either adopted or adapted these theories to examine adoption and diffusion related issues in multitudes of context ranging from societal (Dwivedi and Williams 2008; Hossain et al. 2018; Weerakkody et al. 2009, 2017), to organisational (Martins et al. 2016), and individual scenario (Dwivedi et al. 2006; Kizgin et al. 2018; Slade et al. 2014). This multitude of context and theory presented new challenge of plurality to IS researchers in terms of selecting appropriate theory while undertaking a new study (Dwivedi et al. 2015; Tamilmani et al. 2017).

Venkatesh et al. (2003) developed comprehensive Unified Theory of Acceptance and Use of Technology (UTAUT) to address the issue of plurality based on exhaustive review of eight dominant technology adoption models after elimination of similar/redundant constructs (see Venkatesh et al. 2003 for review). UTAUT theory was developed in the organisational context emphasizing on the utilitarian value (extrinsic motivation) of organisational users. UTAUT model was later 
extended to consumer context emphasizing on the hedonic value (intrinsic motivation) of technology users incorporating three new constructs such as: hedonic motivation, price value, and habit into original UTAUT and popularly refereed as UTAUT2 (see Venkatesh et al. 2012 for review). Despite its recent introduction in the year 2012, UTAUT2 has already garnered more than 5000 citations in Google Scholar alone, it has been frequently cited in IS and other fields, thus emphasising its impact on IS and beyond. Nevertheless, UTAUT2 is faced with similar problem as its predecessor UTAUT yielding inconsistent results essentially for the same research question (i.e. Understanding individual technology adoption). King and $\mathrm{He}$ (2005) noticed this problem are not confined only to IS domain but prevalent in many other mature research streams such as social sciences. They also observed, in comparison to social and behavioural sciences; IS researchers scarcely employed Meta-analysis - a quantitative literature synthesis technique used in mature research streams for knowledge accumulation through integration of results from previous findings and studies(Glass 1976; Kapoor et al. 2014).

The preceding discussion underscores the centrality of two major things. First, UTAUT2 as most comprehensive theory in understanding individual technology adoption and use. Second, meta-analysis technique as a tool to shed light on operationalization of established theoretical models through collation, analysis, and synthesis of existing research findings (Dwivedi et al., 2017). Meta-analysis technique is gaining attention from IS scholars, but most of existing metaanalysis studies focused on established theories such as TAM (King and He 2006; Ma and Liu 2004) and UTAUT (Dwivedi et al. 2011; Taiwo and Downe 2013). There is necessity for similar effort on UTAUT2 theory, which is gaining popularity in IS research arena. Such an effort will test the boundary conditions of various UTAUT2 path relationships and shed light on their (non)significance. This will provide fruitful directions to future researchers on operationalizing the constructs while adapting UTAUT2 as base model across various context. Thus, the aim of this study is to fulfil this research gap and conduct meta-analysis of studies that have citied and utilized UTAUT2 theory/constructs. The objective of this study will be achieved through the following steps: 1) Locating studies that not only citied but used UTAUT2 theory, 2) Calculating mean reliability of UTAUT2 constructs to evaluate their consistency across studies, and 3) Computing effect sizes of zero-order correlation and path coefficients $(\beta)$ using comprehensive meta-analysis software to understand (non)significance of various UTAUT2 structural relationships.

The remaining sections of this paper are outlined as follows: The next section 2 provide literature synthesis on meta-analytic studies on popular technology adoption models; Section 3 describes research methodology employed to select studies for meta-analysis; The succeeding Section 4 presents findings obtained using comprehensive metaanalysis; The penultimate section 5 presents discussion, implications for theory and practice, followed by limitations and directions for future research. The paper ends with conclusion in section 6 .

\section{Related Work}

Information Systems was conceived as an applied discipline up until the last century primarily drawing upon other reference disciplines such as: psychology, mathematics, computer and management science to name a few (Baskerville and Myers 2002). However, this conventional wisdom has changed as IS discipline has come of age reaching maturity with native theories (e.g. TAM, UATUT) to emerge as reference discipline for others on its own right (Baskerville and Myers 2002). This adds IS to the elite list of mature research stream facing a peculiar problem adding empirical results to the existing pile of information rather than efforts to discover untapped knowledge in completed research findings. Literature synthesis technique like meta-analysis comes to the forefront in such scenarios as knowledge accumulation in matures research streams equally depends upon integration of research findings from the existing studies (Glass 1976). It allows both significant and non-significant effects to be analysed through accumulation of various results taking the relative sample and effect size into consideration. Thus, the overall result on the performance of the theory/model is considered more accurate and credible due to the overarching span of the analysis (King and He 2006). In this case, the model under investigation is UTAUT2.

Davis (1989), TAM model based on TRA with more than 40,000 citations is considered as one of the first native and popular theory in the Information Systems discipline. Researchers had made continuous effort from beginning of this century to synthesize results based on the TAM employing both systematic literature review (Lee et al. 2003; Legris et al. 2003), and meta-analysis techniques (King and He 2006; Ma and Liu 2004). The meta-analysis of King and $\mathrm{He}$ (2006) including as much as 88 published studies (highest among all TAM review studies) from 1500 citations is the most comprehensive literature synthesis to date. This seminal TAM meta-analysis manuscript analysed more than 12,000 observations and provided powerful evidence that perceived usefulness has profound effect on behavioural intention to the extent it mediated the effect of ease of use on most instances. In addition, the moderator analysis on various technology user groups suggested that "student" users may be used as surrogate for professional users, but not in the case of "general" users of technology. In terms of technology use contexts, the moderating effect of internet use was found to be different for 
job task applications, general uses, and office applications. Hence the results from studies based on internet context should not be generalized to studies on other contexts and vice versa (King and He 2006).

There are also substantial amount of meta-analysis and systematic review studies on the another popular native technology adoption theory UTAUT (Dwivedi et al. 2011; Faaeq et al. 2013; Rana et al. 2017; Taiwo and Downe 2013) revealing noteworthy findings on performance of the model and convergence and divergence of the path relationships. For instance systematic review of 450 UTAUT citations revealed that only 43 articles (around 10\%) utilized the theory and the remaining 407 articles (90\%) employed it for general citation purpose (Williams et al. 2011). In addition, systematic review on a larger number, 1267 UTAUT citations revealed only 62 studies (approximately 5\%) utilized the theory and remaining 1205 studies (comprising 95\%) just cited the article for general purposes (Venkatesh et al. 2016). The systemic review also found even if researchers employed UTAUT constructs for empirical evaluation they rarely included moderators in their research model. Along the same lines, Venkatesh et al. (2016) omitted moderators while proposing generalized baseline model to evaluate future technology acceptance. Several studies conducted meta-analysis on UTAUT model to measure their performance and revealed inconsistences among their path relationships and underperformance of the theory on many instances. For instance, Dwivedi et al. (2011) metaanalysis on 43 UTAUT empirical studies found the predictive strength of UTAUT relationships to be lesser in comparison to the original model. Meanwhile, Taiwo and Downe (2013) meta-analysis found that performance expectancy and behavioural intention as the only strongest UTAUT path relationship. Finally, Faaeq et al. (2013) meta-analysis divulged the difficulty in generalizing UTAUT theory as same variables yielded different results across countries with different cultural background.

The preceding review on meta-analytic studies reveal performance expectancy/perceived usefulness as the strongest driver behind individual intention to use focal technology. In addition, results obtained from one technology user type are not generalizable universally to all type of technology users. Furthermore, the predictive ability of technology acceptance models and their various path relationships can vary depend on the context such as difference in culture. Therefore, metaanalysis on UTAUT2 theory can reveal noteworthy findings and actionable insights to researches in the technology acceptance arena.

\section{Research Method}

This study employed combination of two highly compatible techniques such as "systematic review" and "meta-analysis", which when used in tandem can provide a powerful, scientific approach for research synthesis in analysing previous studies that utilized UTAUT2 model (Ismagilova et al. 2019; Littell et al. 2008; Rana et al. 2013; Tamilmani et al. 2018a; Trang and Brendel 2019). The term meta-analysis was first coined by Glass (1976) referring to analysis of analysis. Metaanalysis is an advanced form of secondary analysis to establish true effect size of various relationships of population through accumulation of effect sizes from individual studies facilitated by statistical techniques (Dwivedi et al. 2017; Field 2001). It illuminates discovery of new knowledge that is undetectable otherwise in the isolated parcels of data scattered amongst individual "primary" studies (Schmidt 1992). Extant literature review on meta-analysis revealed its four major purposes. First, it functions as a statistical tool to correct sampling and measurement errors (Schmidt and Hunter 2014). Second, it allows inclusion of studies with non-significant and contradictory results to derive collective conclusion (Sabherwal et al. 2006). Third, it serves as a useful method for literature synthesis to highlight existing knowledge gaps (Lee et al. 2003; Ma and Liu 2004; Wu and Lederer 2009). Fourth, as an operative instrument for hypothesis testing through conceptual model development (Sabherwal et al. 2006; Sharma and Yetton 2003; Wu and Lederer 2009). For the above mention reasons, meta-analysis has won widespread recognition as an indispensable tool to provide rigours, unbiased, trustworthy interventions through clarification and synthesis of existing research findings and preferred over traditional narrative assessment of conducting literature review (Dwivedi et al. 2019; Eden 2002). Majority of the studies employed metaanalysis on either fixed effect basis or random effects basis. "Random effects" basis considers individual studies in metaanalysis as part of large population of studies on a given topic. However, the alternative "fixed effect" model considers effect size as it is for all studies in the population representing a "homogenous" case. "Random effect" models for metaanalysis is preferred over "fixed effect" models as the later overstate the degree of precision in meta-analysis findings (Hunter and Schmidt 2000). Furthermore, random effect model is considered more realistic as it allows the researcher to make generalization about the research domain as a whole without restricting the findings only to studies involved in meta-analysis (Field 2001). Considering the above advantages, this study employed random effect model for metaanalysis.

\subsection{Sample}

In order to locate studies needed for meta-analysis, this study employed "citied reference search" method in bibliographic databases such as the Scopus and Web of Science that cited UTAUT2 article i.e. (Venkatesh et al. 2012) from March 2012 to March 2017 (Gurzki and Woisetschlaeger 2017). The cited 
reference search resulted in 1320 citations with contribution of 497 citations from Web of Science and 823 from Scopus. On further scrutiny, it was found 452 citations were common in both databases resulting in 868 unique citations for UTAUT2, which are sum of Scopus unique citations (371), overlap (452) and Web of Science unique citations (45). The next stage of screening involved checking availability of fully downloadable articles from 868 citations that resulted in 650 articles for next stage. Out of 650 articles, only 147 utilized at least one UTAUT2 construct, the remaining 503 articles just citied UTAUT2 for generic reason (see Tamilmani et al. 2017 for review) and hence eliminated from further stages of this study. Since, journals are more inclined to publish studies with significant results, this study considered studies from non-journal sources such as dissertations, books and conference proceedings for meta-analysis to refrain from publication bias ( $\mathrm{Wu}$ and Du 2012). There were no UTAUT2 based studies from books and dissertations indexed by Scopus and Web of Science databases. Table 1 shows the spread of top 20 journals/conferences that published two or more UTAUT2 papers. Computers in Human Behaviour journal emerged as the topmost with ten UTAUT2 papers; AMCIS was not far behind with nine papers at second, and ECIS occupied third spot with six papers. Meanwhile, 77 journals/conferences each published at least one UTAUT2 paper.

\subsection{Coding}

Coding rules were developed and deployed to ensure consistency among studies included for meta-analysis. Researchers established stringent criteria for including and excluding studies to meta-analysis stage from initial pool of 147 UTAUT2 manuscripts. This study selected manuscripts for metaanalysis only when they met all of the following three major criteria: First, they were empirical not conceptual studies and tested at least one construct from UTAUT2 theory (Dwivedi et al. 2019). Second, reported correlation matrix with Pearson correlation (r) for various relationships amongst the dependant and independent constructs or other statistics that may be converted to Pearson correlation (r) (see Wu and Lederer 2009) and third, reported data for the path coefficients (standardized) $(\beta)$, reliability of constructs (Cronbach's $\alpha$ ), and sample size (King and He 2006; Rana et al. 2015). Then the researchers, carefully checked and compared statistical data of studies with each other to avoid duplication and to ensure only distinct studies are included in the meta-analysis (Ma and Liu 2004; Wu and Du 2012). Only one study was included for analysis when two or more studies reported findings using the same data such as articles and proceedings. On the contrary, when a study reported multiple datasets obtained from different samples, each dataset was included for analysis and treated as an independent study. This method of treatment is appropriate and does not violate any assumption of meta-analysis (Hunter et al. 1982; Wu and Du 2012).

\subsection{Analysis}

Firstly, this study analysed the mean reliability of various UTAUT2 constructs to evaluate their internal consistency. Subsequently, researchers conducted meta-analysis of collected data to determine cumulative value of correlation coefficient $(r)$ and path coefficients $(\beta)$ for various exogenous/ independent variables (I.V) and endogenous/dependent variables (D.V). This facilitated researchers to determine convergence and divergence among various UTAUT2 path relationships and their correlations. This study conducted metaanalysis on "random effect basis" using comprehensive meta-analysis software downloaded from the www.metaanalysis.com website. This assumed that the individual studies were random samples taken from population with varying effect sizes such that the overall results are generalizable across the domain. In doing so, meta-analysis assumptions have incorporated both within-study and between study variance to provide more conservative significance test result (King and He 2006). Table 2 summaries all possible relationships among nine UTAUT2 constructs namely: 1) Performance Expectancy (PE); 2) Effort Expectancy (EE); 3) Social Influence (SI); 4) Facilitating Conditions (FC); 5) Hedonic Motivation (HM); 6) Price Value (PV); 7) Habit (HA); 8) Behavioural Intention (BI); 9) Use Behaviour (UB) and their moderators age, gender, and experience (see Venkatesh et al. 2012, p. 160 for model). In total, ten relationships existed between all UTAUT2 constructs without moderator, whereas the number of relationships surged to 25 with effects of moderator (see Table 2 for complete list).

This study adapted meta-analytic approach of Rana et al. (2015) and included only UTAUT2 relationships that are examined three or more times to obtain efficient meta-analysis correlation coefficient $(r)$ and path coefficients $(\beta)$. Only the core UTAUT2 relationships without moderator from Table 2 fulfilled this criterion and were included for meta-analysis. Since the purpose of this study was to evaluate performance of UTAUT2 model, relationships among constructs other than UTAUT2 were not included for meta-analysis.

However, researchers often extend the UTAUT2 model with other popular theories and constructs depending upon the research context and focal phenomenon. Therefore, it is worth mentioning most popular UTAUT2 extensions; Though this study will only focus on UTAUT2 based relationships summarised in Table 2. An in-depth examination of UTAUT2 extensions revealed five constructs such as 'trust', 'perceived risk', 'self-efficacy', 'attitude', and 'personal innovativeness' as the popular extensions with three or more examinations (Table 3 ). In terms of the path relationships, 'Trust' emerged as the most popular UTAUT2 extension with 13 
Table 1 Spread of UTAUT2 articles approach adapted from (King and $\mathrm{He} 2006$ )

\begin{tabular}{llc}
\hline Rank & Journal/Conference & Count \\
\hline 1 & Computers in Human Behaviour & 10 \\
2 & Americas Conference on Information Systems (AMCIS) & 9 \\
3 & European Conference on Information Systems (ECIS) & 6 \\
4 & Pacific Asia Conference on Information Systems (PACIS) & 5 \\
5 & Hawaii International Conference on System Sciences (HICSS) & 4 \\
6 & Industrial Management and Data Systems & 4 \\
7 & International Conference on Information Systems (ICIS) & 4 \\
8 & Journal of Retailing and Consumer Services & 3 \\
9 & International Journal of Hospitality Management & 3 \\
10 & Cogent Business \& Management & 2 \\
11 & Computers and Education & 2 \\
12 & Conference on e-Business, e-Services and e-Society & 2 \\
13 & Information Systems Frontiers & 2 \\
14 & International Journal of Information Management & 2 \\
15 & Journal of Air Transport Management & 2 \\
16 & Journal of Computer Information Systems & 2 \\
17 & Journal of Theoretical and Applied Information Technology \\
18 & Portland International Conference on Management of Engineering and Technology & 2 \\
19 & Psychology and Marketing & 2 \\
20 & Telematics and Informatics & 2 \\
& Others & 77 \\
\hline
\end{tabular}

examinations on behavioural intention with only one nonsignificant examination. 'Perceived risk' emerged as the second most popular extension with nine examinations including two non-significant results. The third most popular UTAUT2 extension 'self-efficacy' involved five examinations in total with four significant and one non-significant result. The remaining two attributes attitude and personal innovativeness had three examinations each on behavioural intention that were only significant.

\section{Findings}

This section presents findings from UTAUT2 constructs reliability, correlations, and their path relationships across 60 studies. The number of studies varies for every relationship in the findings Tables 4 to 5 as all UTAUT2 constructs are not incorporated by every study. However, they all measured at least one UTAUT 2 core relationships (Fig. 1).

\subsection{Reliability of UTAUT2 Constructs}

Reliability also popularly known as Cronbach's alpha $(\alpha)$ is a measure of internal consistency that demonstrates the extent to which all measurement items on a scale measure one construct (Heale and Twycross 2015). The value of $\alpha$ is determined through number of quality measurement items in a construct, their inter relatedness and homogeneity (Cortina 1993). Table 4 and Fig. 2 provide descriptive statistics of Cronbach's alpha $(\alpha)$ of various UTAUT2 constructs across meta-analytic studies. Constructs with single measurement item have Cronbach's alpha $(\alpha)$ of one and hence are excluded from analysis. Since, internal consistency is a measure of item-to-item correlation, at least two measurement items are required to measure Cronbach's alpha $(\alpha)$ for a construct (Heale and Twycross 2015; King and He 2006). The value of Cronbach's alpha $(\alpha)$ ranges from 0 to 1 , higher the value of $\alpha$ higher the reliability of construct and measurement scale used for survey (Santos 1999).Constructs with Cronbach's alpha $(\alpha)$ value of 0.6 or more are deemed to be reliable (Nunnally 1978). Table 4 reveals that all UTAUT2 constructs used in metaanalysis are reliable since their average reliability were well above 0.6 with negligible variance. FC had the least minimum and average reliability values of 0.63 and 0.837 respectively across all constructs. Meanwhile. SI had the maximum reliability value of 0.989 and EE emerged as the construct of highest average reliability with value of 0.899 . The box plot in Fig. 2 reveals the average reliability value of FC as 0.837 and UB as 0.840 are the lowest among all constructs. The skewed upper quartile reliability values of UB with border range confirms its highest variance of 0.0071 attributable to the least sample size of ten. 
Table 2 Summary of UTAUT2 relationships Source: Venkatesh et al. (2012)

\begin{tabular}{|c|c|c|c|c|}
\hline \multirow[t]{2}{*}{ Sl. No } & \multirow{2}{*}{$\begin{array}{l}\text { Path relationship without } \\
\text { moderator } \\
\text { I.V. } \rightarrow \text { D.V. }\end{array}$} & \multirow[t]{2}{*}{ S1. No } & \multicolumn{2}{|c|}{ Path relationship with moderator } \\
\hline & & & I.V. $\rightarrow$ D.V. & Moderator \\
\hline \multirow[t]{2}{*}{1} & \multirow[t]{2}{*}{$\mathrm{PE} \rightarrow \mathrm{BI}$} & 1 & \multirow[t]{2}{*}{$\mathrm{PE} \rightarrow \mathrm{BI}$} & Age \\
\hline & & 2 & & Gender \\
\hline \multirow[t]{3}{*}{2} & \multirow[t]{3}{*}{$\mathrm{EE} \rightarrow \mathrm{BI}$} & 3 & \multirow[t]{3}{*}{$\mathrm{EE} \rightarrow \mathrm{BI}$} & Age \\
\hline & & 4 & & Gender \\
\hline & & 5 & & Experience \\
\hline \multirow[t]{3}{*}{3} & \multirow[t]{3}{*}{$\mathrm{SI} \rightarrow \mathrm{BI}$} & 6 & \multirow[t]{3}{*}{$\mathrm{SI} \rightarrow \mathrm{BI}$} & Age \\
\hline & & 7 & & Gender \\
\hline & & 8 & & Experience \\
\hline \multirow[t]{3}{*}{4} & \multirow[t]{3}{*}{$\mathrm{FC} \rightarrow \mathrm{BI}$} & 9 & \multirow[t]{3}{*}{$\mathrm{FC} \rightarrow \mathrm{BI}$} & Age \\
\hline & & 10 & & Gender \\
\hline & & 11 & & Experience \\
\hline \multirow[t]{3}{*}{5} & \multirow[t]{3}{*}{$\mathrm{HM} \rightarrow \mathrm{BI}$} & 12 & \multirow[t]{3}{*}{$\mathrm{HM} \rightarrow \mathrm{BI}$} & Age \\
\hline & & 13 & & Gender \\
\hline & & 14 & & Experience \\
\hline \multirow[t]{2}{*}{6} & \multirow[t]{2}{*}{$\mathrm{PV} \rightarrow \mathrm{BI}$} & 15 & \multirow[t]{2}{*}{$\mathrm{PV} \rightarrow \mathrm{BI}$} & Age \\
\hline & & 16 & & Gender \\
\hline \multirow[t]{3}{*}{7} & \multirow[t]{3}{*}{$\mathrm{HA} \rightarrow \mathrm{BI}$} & 17 & \multirow[t]{3}{*}{$\mathrm{HA} \rightarrow \mathrm{BI}$} & Age \\
\hline & & 18 & & Gender \\
\hline & & 19 & & Experience \\
\hline \multirow[t]{2}{*}{8} & \multirow[t]{2}{*}{$\mathrm{FC} \rightarrow \mathrm{UB}$} & 20 & \multirow[t]{2}{*}{$\mathrm{FC} \rightarrow \mathrm{UB}$} & Age \\
\hline & & 21 & & Experience \\
\hline \multirow[t]{3}{*}{9} & \multirow[t]{3}{*}{$\mathrm{HA} \rightarrow \mathrm{UB}$} & 22 & \multirow[t]{3}{*}{$\mathrm{HA} \rightarrow \mathrm{UB}$} & Age \\
\hline & & 23 & & Gender \\
\hline & & 24 & & Experience \\
\hline 10 & $\mathrm{BI} \rightarrow \mathrm{UB}$ & 25 & $\mathrm{BI} \rightarrow \mathrm{UB}$ & Experience \\
\hline
\end{tabular}

\subsection{Meta-Analysis of UTAUT2 Correlations}

Table 5 presents the summary of zero-order random correlations of all ten UTAUT2 relationships across 60 studies. The results reveal that the effect sizes of all correlation were significant at $\mathrm{p}<0.00$ level. Meta-analysis correlation (r) for all relationships were considerably higher to their corresponding UTAUT2 correlations reaffirming on the cumulative effect of
Table 3 Most Popular UTAUT2 extensions

\begin{tabular}{|c|c|c|c|c|}
\hline I.V & D.V & \# & Significant Examinations & $\begin{array}{l}\text { Non-significant } \\
\text { examinations }\end{array}$ \\
\hline TR & $\mathrm{BI}$ & 13 & $\begin{array}{l}\text { Alalwan et al. (2015), (2017); Escobar-Rodríguez and } \\
\text { Carvajal-Trujillo (2014); Fakhoury and Aubert (2015); Jia } \\
\text { et al. (2015)(adopters and non-adopters); Lallmahomed et al. } \\
\text { (2017); Qasim and Abu-Shanab (2016); Pfeiffer et al. } \\
\text { (2016); Shaw (2014); Slade et al. (2015a); Zhai and Huang } \\
\text { (2016); }\end{array}$ & Slade et al. (2015b) \\
\hline PR & $\mathrm{BI}$ & 9 & $\begin{array}{l}\text { Alalwan et al. (2016); Gao et al. (2015a)(Three samples); } \\
\text { Koenig-Lewis et al. (2015); Slade et al. (2015a), (b) }\end{array}$ & $\begin{array}{l}\text { An et al. (2016); Zhai } \\
\text { and Huang (2016) }\end{array}$ \\
\hline SE & $\mathrm{BI}$ & 5 & $\begin{array}{l}\text { Alalwan et al. (2015); Lallmahomed et al. (2017); Gao et al. } \\
\text { (2015a) (Full and Medical sample) }\end{array}$ & $\begin{array}{l}\text { Gao et al. (2015a) } \\
\text { (Fitness sample) }\end{array}$ \\
\hline AT & $\mathrm{BI}$ & 3 & Hajli and Lin (2016); Koohikamali et al. (2017) (Two Samples) & None \\
\hline PIN & $\mathrm{BI}$ & 3 & $\begin{array}{l}\text { An et al. (2016); Pfeiffer et al. (2016); Kourouthanassis et al. } \\
\text { (2015) }\end{array}$ & None \\
\hline
\end{tabular}

[Legend: \#: Number of studies; AT: Attitude; D.V: Dependant variable; I.V: Independent Variable; PIN: Personal innovativeness; PR: Perceived risk; SE: Self-efficacy; TR: Trust]. 
Table 4 UTAUT2 constructs descriptive statistics: Method adapted from (King and He 2006)

\begin{tabular}{|c|c|c|c|c|c|c|c|c|c|}
\hline & PE & $\mathrm{EE}$ & SI & $\mathrm{FC}$ & $\mathrm{HM}$ & PV & HA & $\mathrm{BI}$ & UB \\
\hline Average Reliability & 0.895 & 0.899 & 0.883 & 0.837 & 0.888 & 0.895 & 0.890 & 0.896 & 0.840 \\
\hline Minimum & 0.749 & 0.799 & 0.710 & 0.630 & 0.736 & 0.799 & 0.737 & 0.698 & 0.690 \\
\hline Maximum & 0.972 & 0.980 & 0.989 & 0.970 & 0.980 & 0.980 & 0.970 & 0.980 & 0.940 \\
\hline Variance & 0.0029 & 0.0019 & 0.0042 & 0.0044 & 0.0040 & 0.0026 & 0.0041 & 0.0042 & 0.0071 \\
\hline Number of Samples & 56 & 53 & 45 & 33 & 36 & 19 & 18 & 56 & 10 \\
\hline
\end{tabular}

meta-analysis. However, meta-analysis(r) correlation ranking based on strength showed complete departure from UTAUT2 correlations (r) ranking. Among, all UTAUT2 relationships, Habit was the most highly correlated construct to behavioural intention with $\mathrm{HA} \leftrightarrow \mathrm{BI}$ meta-analysis(r) of 0.635. Meanwhile, facilitating conditions was the least correlated construct to use behaviour having $\mathrm{FC} \leftrightarrow \mathrm{UB}$ meta-analysis(r) of 0.399 . The meta-analysis correlation(r) for remaining relationships fell in between the values of these two relationship types. The 95\% confidence interval of $\mathrm{EE} \leftrightarrow \mathrm{BI}$ correlations ranging from Low (r) (0.437) to High(r) (0.524) was the narrowest among all UTAUT2 correlations such that it can explain at least one confidence within the extent of variance

Figure 3. (a-j) displays the correlation distribution of UTAUT2 relationships across various studies. The correlations of $\mathrm{EE} \leftrightarrow \mathrm{BI}, \mathrm{FC} \leftrightarrow \mathrm{UB}, \mathrm{SI} \leftrightarrow \mathrm{BI}$, and $\mathrm{FC} \leftrightarrow \mathrm{BI}$ were all positive and normally distributed through narrow range comprising top four least standard deviation (S.D) values of 0.16 , $0.165,0.17$ and 0.171 respectively without having much variation between studies. Meanwhile, the histogram of $\mathrm{PE} \leftrightarrow \mathrm{BI}$ with long left tail confirms its skewness towards lower correlation values having minimum value of 0.05 .

Furthermore, the correlations of $\mathrm{HA} \leftrightarrow \mathrm{UB}, \mathrm{HM} \leftrightarrow \mathrm{BI}$, and $\mathrm{HA} \leftrightarrow \mathrm{BI}$ got three topmost S.D. values of $0.362,0.212$, and 0.229 respectively underscoring their divergence with negative correlation values forming long left tail distribution curve.
Only these three correlations had negative values of -0.44 , -0.056 and -0.016 respectively reiterating their departure from other UTAUT2 constructs. Finally, the correlations values of $\mathrm{PV} \leftrightarrow \mathrm{BI}$ and $\mathrm{BI} \leftrightarrow \mathrm{UB}$ followed a normal frequency distribution over a range of positive values from as minimum as 0.05 for $\mathrm{BI} \leftrightarrow \mathrm{UB}$ to maximum value of 0.942 for $\mathrm{PV} \leftrightarrow \mathrm{BI}$.

\subsection{Meta-Analysis of UTAUT2 Path Coefficients}

Consistent with TAM meta-analysis study of King and He (2006), this study conducted meta-analysis on all path coefficients ( $\beta$ 's) of UTAUT2 structural model using comprehensive meta-analysis software. Table 6 presents the metaanalysis results of path coefficients $(\beta)$ for all UTAUT2 relationships. The results revealed all the relationships were significant at $p<0.00$ level except for $\mathrm{PV} \rightarrow \mathrm{BI}$ and $\mathrm{FC} \rightarrow \mathrm{UB}$, which were significant at $p<0.012$ and $p<0.001$ respectively. $\mathrm{PE} \rightarrow \mathrm{BI}$ (50 studies), EE $\rightarrow \mathrm{BI}$ (46 studies) and $\mathrm{SI} \rightarrow \mathrm{BI}$ (45 studies) emerged as the three topmost path relationships examined from the UTAUT2 structural model. Meanwhile, $\mathrm{HA} \rightarrow \mathrm{UB}$ (13 studies), FC $\rightarrow \mathrm{UB}$ (15 studies) and $\mathrm{HA} \rightarrow \mathrm{BI}$ (18 studies) were the three least examined UTAUT2 path relationships. This led to further analysis on the outcome variables employed in the 60 UTAUT2 studies. The analysis divulged interesting findings that only 21 studies employed UB as their outcome variable with all of them utilizing BI as their
Table 5. Zero-order random correlations summary: Method adapted from (King and He 2006)

\begin{tabular}{lcllllllll}
\hline $\begin{array}{l}\text { Correlation } \\
\text { Type }\end{array}$ & $\#$ & T.S.S. & $\mathrm{p}(\mathrm{ES})$ & $\begin{array}{l}95 \% \\
\mathrm{~L}(\mathrm{r})\end{array}$ & $\begin{array}{l}95 \% \\
\mathrm{H}(\mathrm{r})\end{array}$ & $\begin{array}{l}\text { UTAUT2 } \\
(\mathrm{r})\end{array}$ & $\begin{array}{l}\text { UTAUT2(r) } \\
\text { Rank }\end{array}$ & Meta(r) & $\begin{array}{l}\text { Meta (r) } \\
\text { Rank }\end{array}$ \\
\hline $\mathrm{HA} \mathrm{BI}$ & 17 & 7873 & 0.000 & 0.541 & 0.714 & 0.40 & 5 & 0.635 & 1 \\
$\mathrm{PE} \mathrm{BI}$ & 55 & 21,990 & 0.000 & 0.561 & 0.664 & 0.44 & 3 & 0.615 & 2 \\
$\mathrm{HM} \mathrm{BI}$ & 35 & 13,700 & 0.000 & 0.516 & 0.638 & 0.37 & 6 & 0.58 & 3 \\
$\mathrm{BI} \mathrm{UB}$ & 19 & 8158 & 0.000 & 0.468 & 0.651 & 0.42 & 4 & 0.566 & 4 \\
$\mathrm{PV} \leftrightarrow \mathrm{BI}$ & 20 & 5891 & 0.000 & 0.416 & 0.64 & 0.29 & 9 & 0.537 & 5 \\
$\mathrm{FC} \leftrightarrow \mathrm{BI}$ & 34 & 14,238 & 0.000 & 0.465 & 0.595 & 0.46 & 2 & 0.533 & 6 \\
$\mathrm{HA} \leftrightarrow \mathrm{UB}$ & 13 & 6820 & 0.000 & 0.317 & 0.658 & 0.49 & 1 & 0.507 & 7 \\
$\mathrm{SI} \leftrightarrow \mathrm{BI}$ & 46 & 19,595 & 0.000 & 0.410 & 0.574 & 0.28 & 10 & 0.496 & 8 \\
$\mathrm{EE} \leftrightarrow \mathrm{BI}$ & 52 & 21,448 & 0.000 & 0.437 & 0.524 & 0.29 & 8 & 0.481 & 9 \\
$\mathrm{FC} \leftrightarrow \mathrm{UB}$ & 17 & 8468 & 0.000 & 0.320 & 0.473 & 0.30 & 7 & 0.399 & 10 \\
\hline
\end{tabular}

Legend: H(r): Highest (correlation); L(r): Lowest (correlation); Meta(r): Meta-analysis correlation; $p$ (ES): Estimated value of $\mathrm{p}$ ( $p$ value); S.D. $(\sigma)$ : Standard deviation; T.S.S.: Total sample size; \#: Number of studies. 
Fig. 1 Meta-analysis flowchart

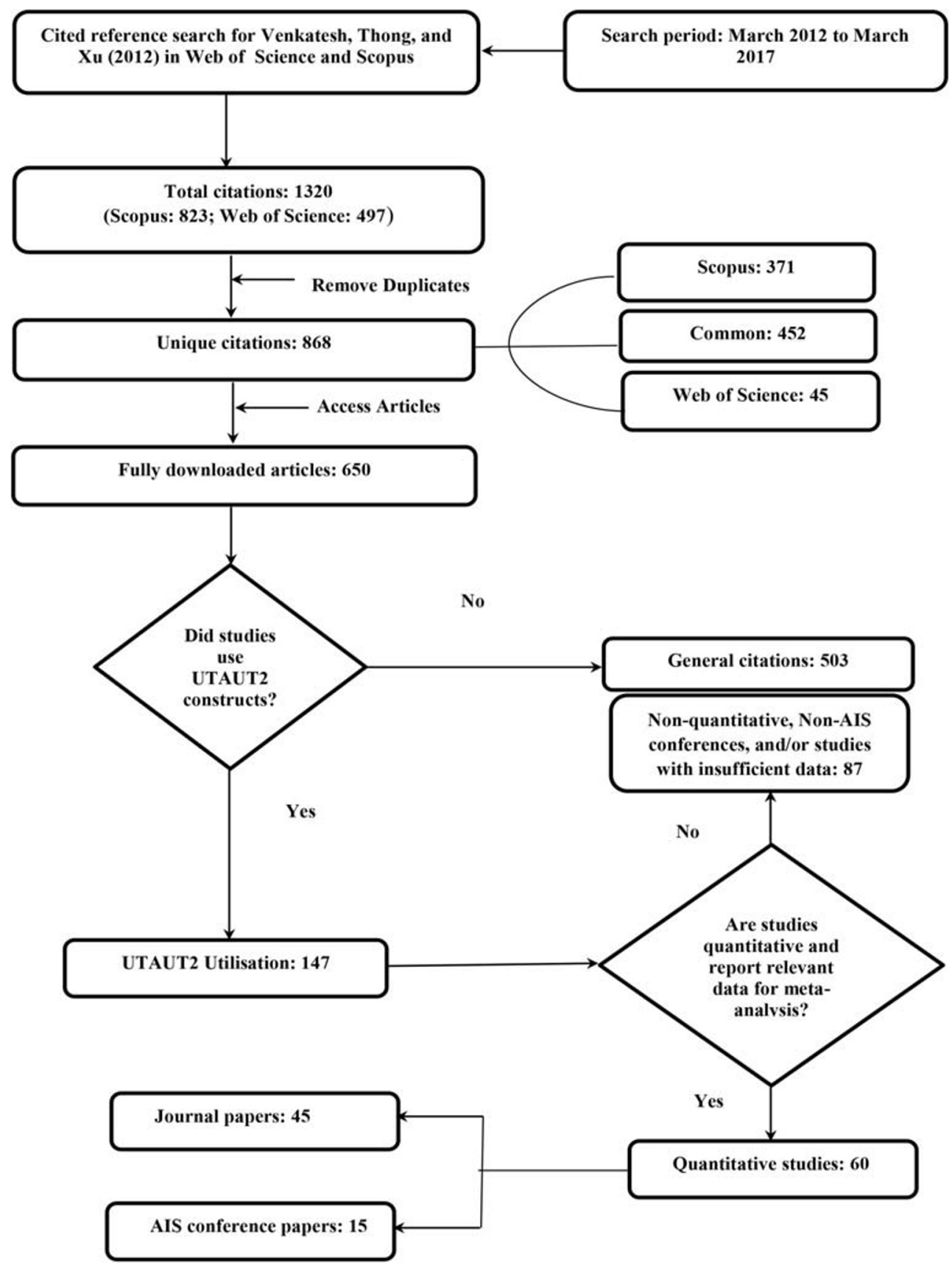

antecedent. Meanwhile, BI emerged as the most operated endogenous variable with 37 studies hypothesizing BI as outcome variable. Finally, there were couple of studies that employed radically new outcome variables apart from BI and UB such as: 1) Job Offer Success (Buettner 2016) and 2) Jobseeker unemployment duration (Huang and Chuang 2016).

Figure 4. (a-j) displays the path coefficients distribution of UTAUT2 relationships across various studies. The metaanalysis $(\beta)$ values were consistent with UTAUT2 $(\beta)$ having minimal difference on either side comprising both higher and lesser values unlike meta-analysis correlation (r) where the values were always higher. The path relationships $\mathrm{BI} \rightarrow \mathrm{UB}$, $\mathrm{HA} \rightarrow \mathrm{BI}$, and $\mathrm{HA} \rightarrow \mathrm{UB}$ emerged as the top three strongest paths amongst all UTAUT2 relationships in the same order with meta-analysis $(\beta)$ values of $0.38,0.276$, and 0.273 respectively. $\mathrm{BI} \rightarrow \mathrm{UB}$ was the strongest and only path comprising all significant values with normal distribution curve underscoring the convergence. Meanwhile, $\mathrm{HA} \rightarrow \mathrm{UB}$ had the highest S.D. (0.239) amid all paths that was demonstrated in divergence of path values extending from as low as -0.13 to as high as 0.675 . The most employed UTAUT2 relationship 
Fig. 2 UTAUT2 Constructs Reliability

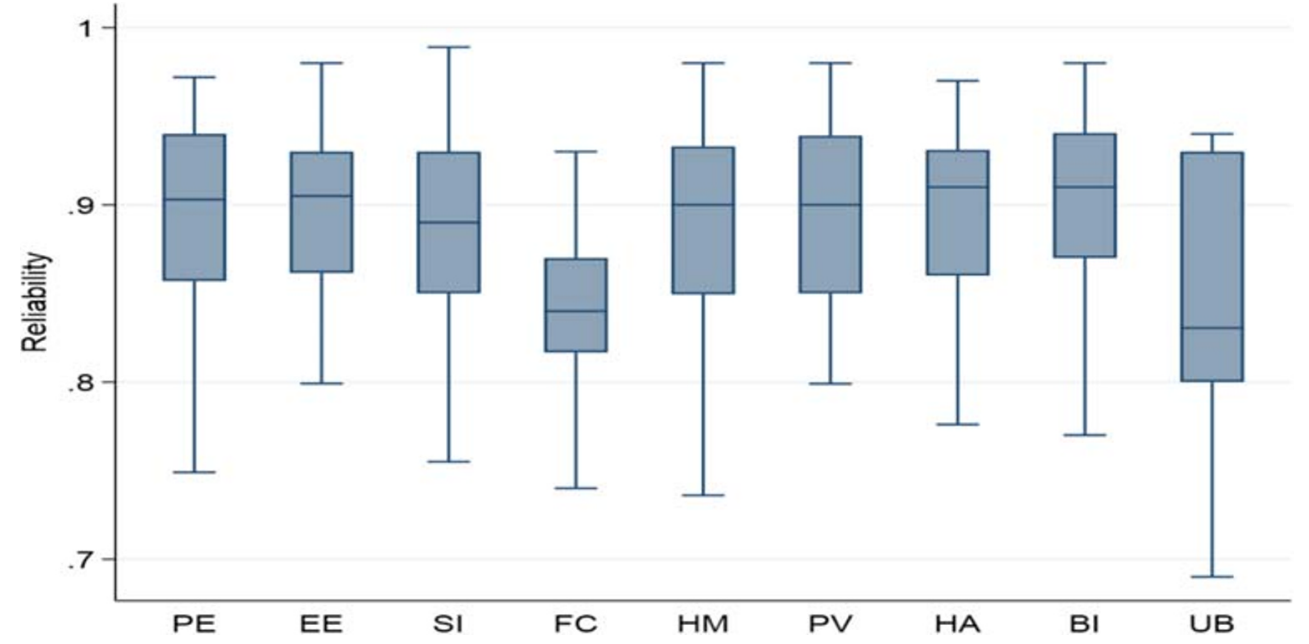

$\mathrm{PE} \rightarrow \mathrm{BI}$ was the fourth strongest path with meta-analysis $(\beta)$ 0.253 and had the most significant values (45 studies) spread over normal distribution curve.

$\mathrm{HM} \rightarrow \mathrm{BI}$ was the fifth strongest path with second highest S.D. (0.197) following unimodal distribution with minimum value of -0.109 and highest maximum value of 0.85 . $\mathrm{FC} \rightarrow \mathrm{UB}, \mathrm{FC} \rightarrow \mathrm{BI}$, and $\mathrm{SI} \rightarrow \mathrm{BI}$ are the next three strongest paths with meta-analysis $(\beta)$ value of $0.181,0.153$, and 0.138 respectively placing them at sixth, seventh and eighth position in the same order. Even though these three paths had negative and non-significant path coefficients, the long right tail distribution confirms their skewness towards higher positive path coefficients over broader range of values.

Moreover, the second least strong path PV $\rightarrow$ BI had metaanalysis $(\beta)$ (0.125) with half of the studies reporting nonsignificant values. The histogram of $\mathrm{PV} \rightarrow \mathrm{BI}$ was denser towards the lower end comprising lower path coefficient values with lone exception of a study by Salim et al. (2016), which reported maximum positive value of 0.714 . Finally, the path $\mathrm{EE} \rightarrow \mathrm{BI}$ despite being the second most frequently examined path was the weakest of all UTAUT2 relationships encompassing least meta-analysis $(\beta)(0.102)$, highest nonsignificant values (20 studies) and lowest minimum path value $(-0.166)$. In contradiction, the histogram of $\mathrm{EE} \rightarrow \mathrm{BI}$ followed normal distribution in the narrowest range including least S.D. (0.117) that laid emphasis on its convergence towards lower non-significant path values.

\section{Discussion}

This study conducted meta-analysis on various UTAUT2 structural paths to unfold their convergence and divergence. UTAUT based theories have been paradox to IS researchers, on one hand, they solved the plurality riddle through elimination of redundant constructs, on the other hand their complex interactions amidst various constructs and moderators hampers the usage of theory as such demanding adaptation of theory to various context (Venkatesh et al. 2016). The trend remained the same in the case of UTAUT2 where moderators could not qualify for meta-analysis due to lack of studies incorporating moderator relationships into their structural model.

\subsection{Summary of Average Reliability (a) and Meta-Analysis of Correlation ( $r$ )}

The average reliability $(\alpha)$ value of UTAUT2 constructs ranged from minimum of 0.837 for facilitating conditions to maximum of 0.899 for effort expectancy. The lower $(\alpha)$ value of constructs could be associated to minimum number of measurement items, low inter-relatedness among the items and heterogeneity of the constructs. On the other hand, constructs with very high $(\alpha)$ approaching the value of one should be used with caution as some of the measurement items could be redundant and testing the same question in different disguise (Tavakol and Dennick 2011). Nevertheless, a maximum $\alpha$ value up to 0.90 is recommend as the desirable level of internal consistency (Streiner 2003). Therefore, all UTAUT2 constructs fall within desirable level of $\alpha$ of 0.90 with effort expectancy having highest average reliability of 0.899 . Although reliability is a good measure of internal consistency of constructs not appropriate enough to evaluate performance of UTAUT2 path relationships.

This brings spotlight onto the meta-analysis findings from correlation (r) and path coefficients $(\beta)$. The meta-analysis correlation (r) strength ranking as seen from Table 5 displayed complete departure from the UTAUT2 model correlations without following any order. Meanwhile, the histograms from Fig. 3. (a-j) displays magnitude and frequency distribution of UTAUT2 correlations amongst all relationships. Although, correlations are better measure than reliability to explain the strength of relationship between two constructs/variables in structural model, the advantage ceases to exist beyond that 


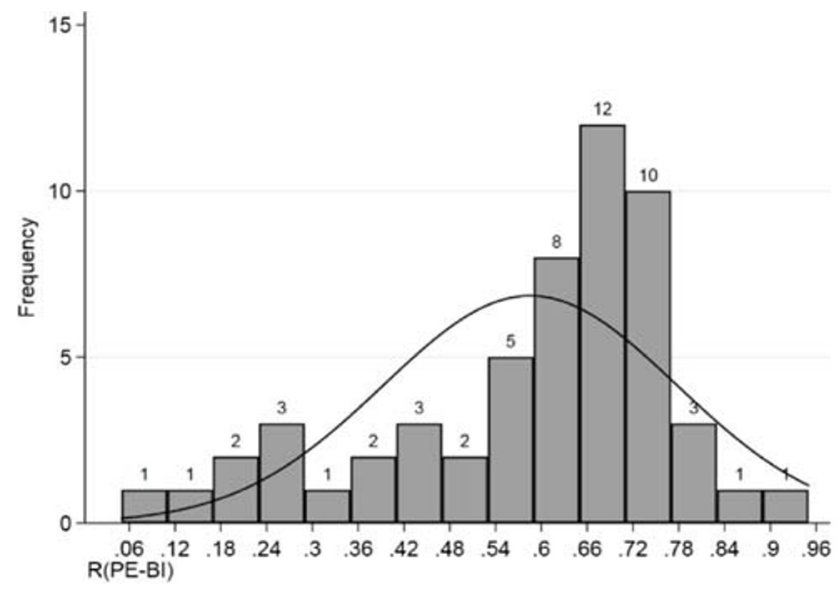

Mean: 0.585 Std. Deviation: 0.192

Minimum: 0.05 Maximum: 0.91

(a)

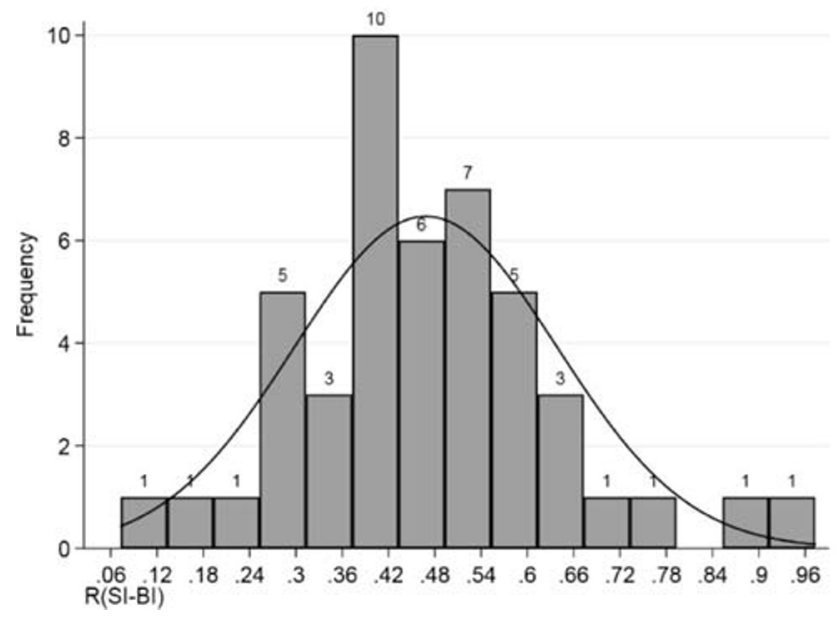

Mean: 0.468 Std. Deviation: 0.170

Minimum: 0.073 Maximum: 0.95

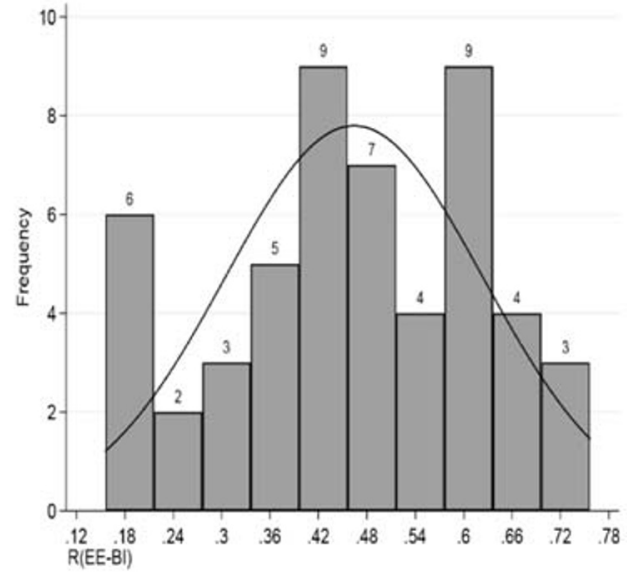

Mean: 0.464 Std. Deviation: 0.160

Minimum: 0.1562 Maximum: 0.7378

(b)

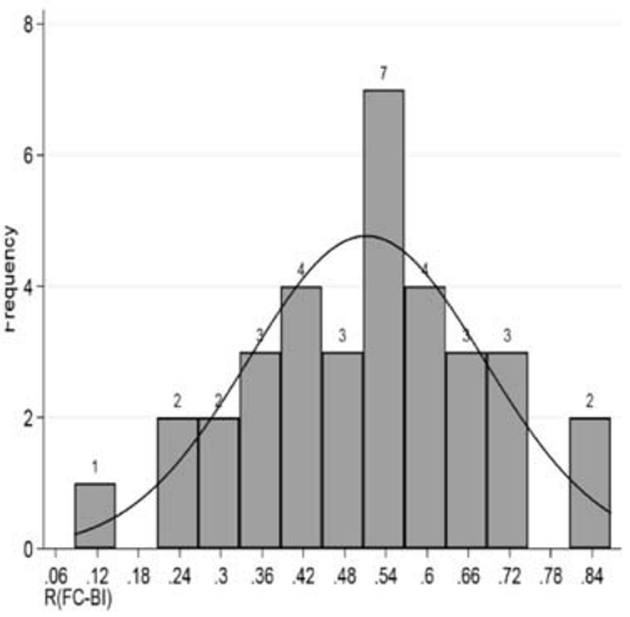

Mean: 0.512 Std. Deviation: 0.171

Minimum: 0.087 Maximum: 0.831

(d)
Fig. 3 (a) Histogram of Correlations (PE-BI). (b) Histogram of Correlations (EE-BI) (c) Histogram of Correlations (SI-BI). (d) Histogram of Correlations (FC-BI) (e) Histogram of Correlations (HM-

point. Since correlations between two constructs is computed standalone based on the measurement items of two constructs under question without taking the effects other constructs in the structural model into account. Thus, path coefficients in structural relationships are better measure than the zero-order correlations to explain the individual's acceptance of new technologies based on UTAUT2 model. Moreover, studies scarcely report correlation matrices and hence most researchers resort to structural relationships to understand significance of various path relationships (King and $\mathrm{He} 2006$ ). In similar vein, this study utilizes meta-analysis path coefficients $(\beta)$ ranking as the major criterion to determine the performance of various UTAUT2 path relationships.
BI) (f) Histogram of Correlations (PV-BI) (g) Histogram of Correlations (HA-BI). (h) Histogram of Correlations (FC-UB) (i) Histogram of Correlations (HA-UB). (j) Histogram of Correlations (BI-UB)

\subsection{Summary of Effect Sizes}

\subsubsection{Top Five UTAUT2 Path Relationships}

Meta-analysis on UTAUT2 path relationships found BI $\rightarrow$ UB as the strongest path with $(\beta)$ value of 0.38 across cumulative sample size of 9436 respondents and 21 studies. This indicates only $35 \%$ (21 studies) employed use behaviour as endogenous variable while with 37 studies comprising $(62 \%)$ still majority of studies of operated BI as endogenous variable. The major cause for this phenomenon is due to long held notion of IS researchers that BI could serve as good surrogate of use behaviour. However, Wu and Du (2012) meta-analysis on BI 


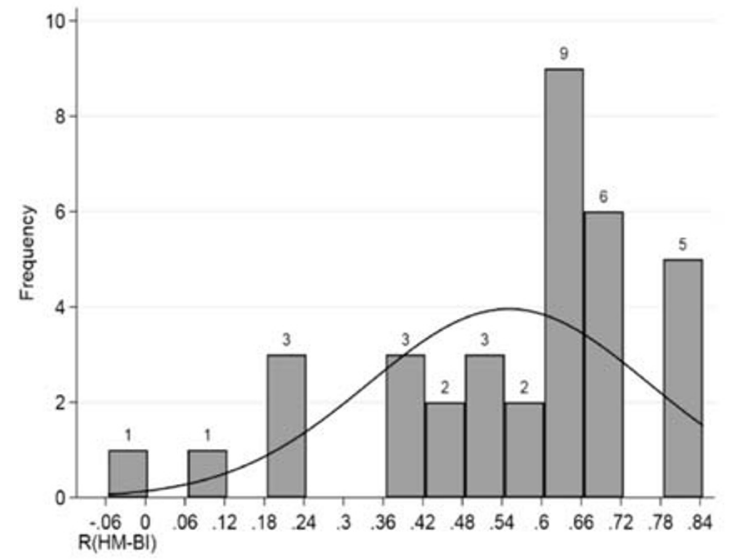

Mean: 0.550 Std. Deviation: 0.212

Minimum: -0.056 Maximum: 0.82

(e)

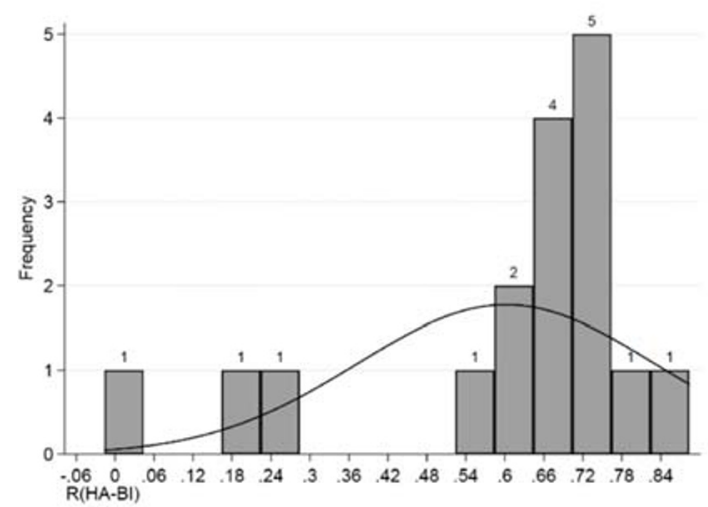

Mean: 0.602 Std. Deviation: 0.229

Minimum: -0.016 Maximum: 0.826

(g)

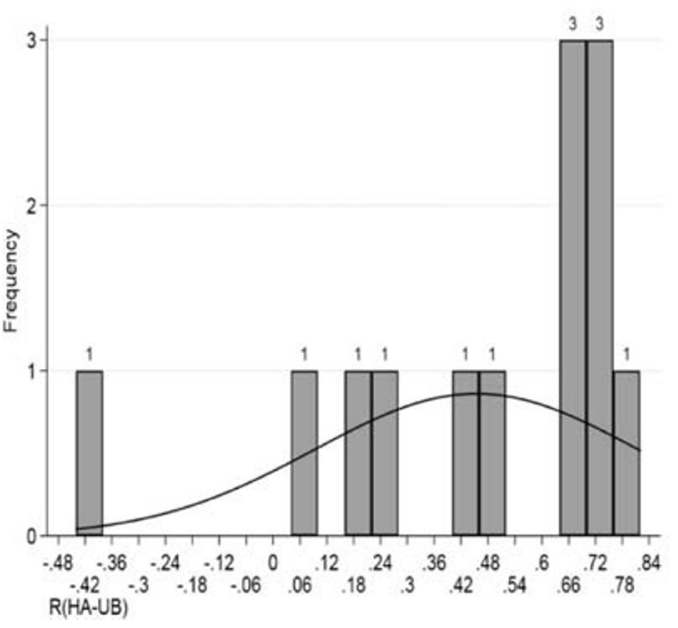

Mean: 0.454 Std. Deviation: 0.362

Minimum: -0.44 Maximum: 0.794

(i)

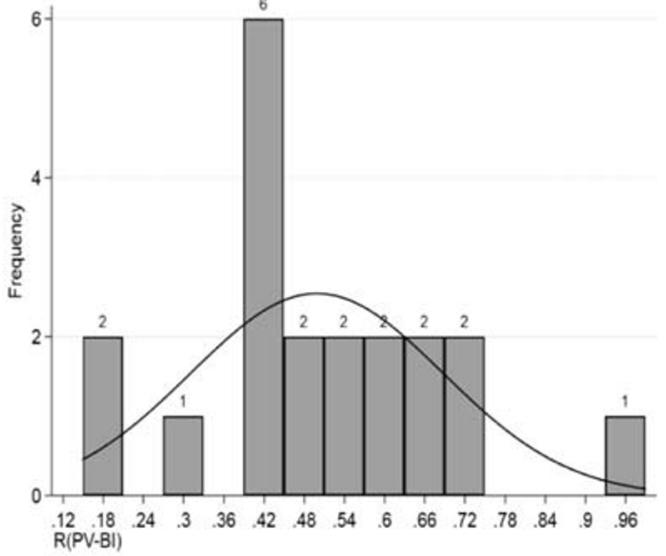

Mean: 0.499 Std. Deviation: 0.188

Minimum: 0.1492 Maximum: 0.942

(f)

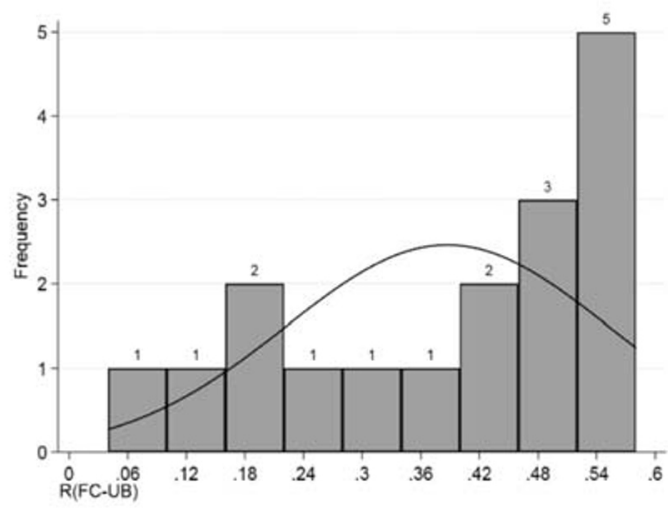

Mean: 0.387 Std. Deviation: 0.165

Minimum: 0.04 Maximum: 0.578

(h)

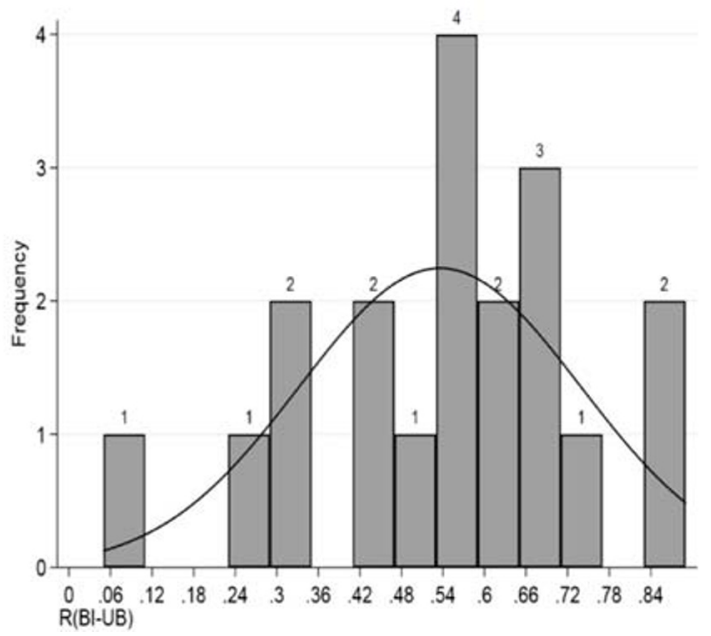

Mean: 0.536 Std. Deviation: 0.203

Minimum: 0.05 Maximum: 0.833

(j)

Fig. 3 (continued) 
Table 6 Meta-analysis of path coefficients $(\beta)$ : Method adapted from (King and He 2006)

\begin{tabular}{llllllllll}
\hline $\begin{array}{l}\text { Path } \\
\text { Relationship }\end{array}$ & $\#$ & T.S.S. & $\begin{array}{l}\mathrm{p} \\
(\mathrm{ES})\end{array}$ & $\begin{array}{l}\text { UTAUT2 } \\
(\beta)\end{array}$ & $\begin{array}{l}\text { UTAUT2 } \\
(\beta) \text { Rank }\end{array}$ & $\begin{array}{l}\text { Meta } \\
(\beta)\end{array}$ & $\begin{array}{l}\text { Meta( } \beta) \\
\text { Rank }\end{array}$ & $\begin{array}{l}\text { Sig } \\
(\beta)\end{array}$ & $\begin{array}{l}\text { Non- } \\
\text { Sig }(\beta)\end{array}$ \\
\hline $\mathrm{BI} \rightarrow \mathrm{UB}$ & 21 & 9436 & 0.000 & 0.33 & 1 & 0.380 & 1 & 21 & 0 \\
$\mathrm{HA} \rightarrow \mathrm{BI}$ & 18 & 8501 & 0.000 & 0.32 & 2 & 0.276 & 2 & 15 & 3 \\
$\mathrm{HA} \rightarrow \mathrm{UB}$ & 13 & 6820 & 0.000 & 0.24 & 3 & 0.273 & 3 & 11 & 2 \\
$\mathrm{PE} \rightarrow \mathrm{BI}$ & 50 & 20,879 & 0.000 & 0.21 & 5 & 0.253 & 4 & 45 & 5 \\
$\mathrm{HM} \rightarrow \mathrm{BI}$ & 33 & 13,036 & 0.000 & 0.23 & 4 & 0.246 & 5 & 29 & 4 \\
$\mathrm{FC} \rightarrow \mathrm{UB}$ & 15 & 7878 & 0.001 & 0.15 & 8 & 0.181 & 6 & 13 & 2 \\
$\mathrm{FC} \rightarrow \mathrm{BI}$ & 31 & 12,707 & 0.000 & 0.16 & 6 & 0.153 & 7 & 21 & 10 \\
$\mathrm{SI} \rightarrow \mathrm{BI}$ & 45 & 18,856 & 0.000 & 0.14 & 9 & 0.138 & 8 & 31 & 14 \\
$\mathrm{PV} \rightarrow \mathrm{BI}$ & 20 & 5891 & 0.012 & 0.14 & 9 & 0.125 & 9 & 10 & 10 \\
$\mathrm{EE} \rightarrow \mathrm{BI}$ & 46 & 18,948 & 0.000 & 0.16 & 6 & 0.102 & 10 & 26 & 20 \\
\hline
\end{tabular}

and UB constructs cautions such notion of IS researchers because it's not appropriate to study user behaviour without assessing their actual system usage. However, BI is good indicator of future technology use since majority of consumer technologies are still evolving. Moreover, none of studies reported non-significant value for $\mathrm{BI} \rightarrow \mathrm{UB}$ underscoring strength of this path.

The two newly introduced habit-based paths $\mathrm{HA} \rightarrow \mathrm{BI}$ and $\mathrm{HA} \rightarrow \mathrm{UB}$ emerged as second and third strongest paths like the strength of UTAUT2 paths. While the former HA $\rightarrow$ BI path relationship was based on instant activation perspective (IAP) (Ajzen and Fishbein 2000) in which use behaviour is considered as an accelerated form of conscious use and perceived as function of behavioural intention. The later, HA $\rightarrow U B$ path relationship based Habit/automaticity perspective (HAP) (Kim et al. 2005), states use behaviour occur automatically as a result of past use habits due to habit/automaticity without formation of evaluation and intention. These relationships together were non-significant only on five instances and need more validation in terms of number of studies. Habitual behaviour is best predictor of subsequent technology use of applications used on daily basis. In other words, HA $\rightarrow U B$ is better hypothesis in understanding consumer adoption of well-established and mature technologies. On the other hand behavioural intention (BI) is better predictor of habit and subsequent use behaviour (UB) for new and rarely used technology applications (Ouellette and Wood 1998; Tamilmani et al. 2018b).

$\mathrm{PE} \rightarrow \mathrm{BI}$ was the fourth strongest path and most employed UTAUT2 relationship with 50 studies (see Table 6) and only five $(10 \%)$ of the 50 studies reported non-significant values for this path relationship. These findings are consistent with other individual technology acceptance models of metaanalysis such as TAM (see King and He 2006) that revealed perceived usefulness a similar construct to performance expectancy as the most significant predictor of behavioural intention. This underscores the predictive validity of performance expectancy in determining individual behavioural intention towards technology acceptance in UTAUT2 model and beyond.

The fifth strongest path $\mathrm{HM} \rightarrow \mathrm{BI}$ was by far the most utilized new construct in the UTAUT2 model with 33 studies in comparison to its counterparts such as HA (31 studies including both $\mathrm{BI}$ and UB relationship) and PV (20 studies). For the $\mathrm{HM} \rightarrow \mathrm{BI}$ path, 29/33 studies around (88\%) reported significant values with only remaining $12 \%$ reporting nonsignificant values. The four studies that reported nonsignificant values were more focused on utilitarian value of consumers rather than hedonic motivation such as learning management system (Ain et al. 2016), online air ticket purchases (Tomás Escobar-Rodríguez and Carvajal-Trujillo 2013), medical respondent samples in wearable healthcare technology (Gao et al. 2015a) and mobile payment (Oliveira et al. 2016). Therefore, researchers should be circumspect of using $\mathrm{HM} \rightarrow \mathrm{BI}$ path relationship in studies focused on utilitarian value(Tamilmani et al. 2019).

\subsubsection{Bottom Five Strongest UTAUT2 Path Relationships}

The paths $\mathrm{FC} \rightarrow \mathrm{UB}$ and $\mathrm{FC} \rightarrow \mathrm{BI}$ were the sixth and seventh strongest path respectively in the UTAUT2 model as per metaanalysis $(\beta)$ findings. Unlike, UTAUT model based on organisational context where the hypothesis was only from $\mathrm{FC} \rightarrow \mathrm{UB}$, in the UTAUT2 model based on consumer context the hypothesis was both from $\mathrm{FC} \rightarrow \mathrm{UB}$ and from $\mathrm{FC} \rightarrow \mathrm{BI}$. The reason being in organisational context the facilitating conditions available to organisation users does not vary from user to user and remains invariant for all users of technology. Meanwhile, in consumer context facilitating conditions can

Fig. 4 (a) Histogram of Path Coefficients (PE-BI) (b) Histogram of Path Coefficients (EE-BI) (c) Histogram of Path Coefficients (SI-BI) (d) Histogram of Path Coefficients (FC-BI) (e) Histogram of Path Coefficients (HM-BI) (f) Histogram of Path Coefficients (PV-BI) (g) Histogram of Path Coefficients (HA-BI) (h) Histogram of Path Coefficients (FC-UB) (i) Histogram of Path Coefficients (HA-UB) (j) Histogram of Path Coefficients (BI-UB) 


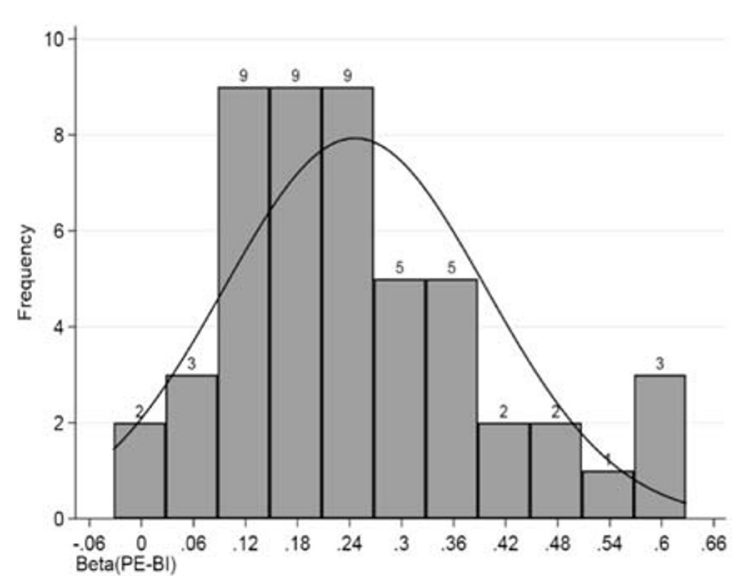

Mean: 0.246 Std. Deviation: 0.151

Minimum: -0.0321 Maximum: 0.61

(a)

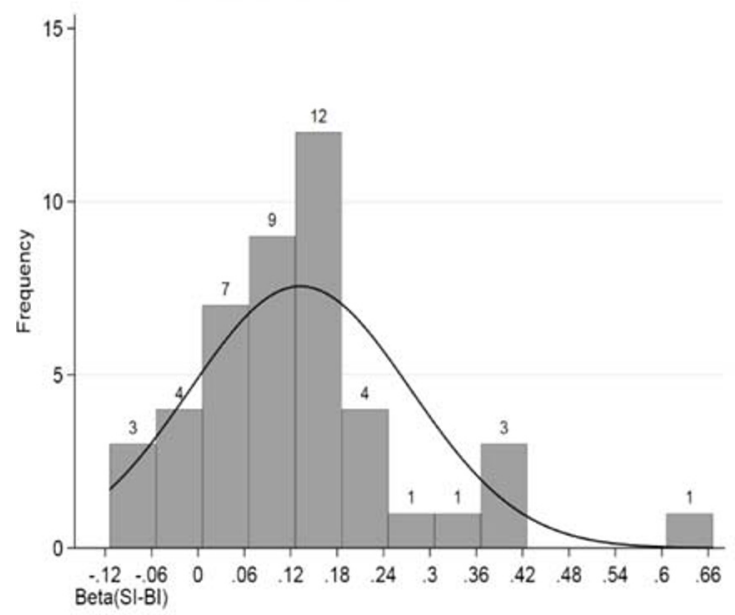

Mean: 0.133 Std. Deviation: 0.143

Minimum: -0.114 Maximum: 0.63

(c)

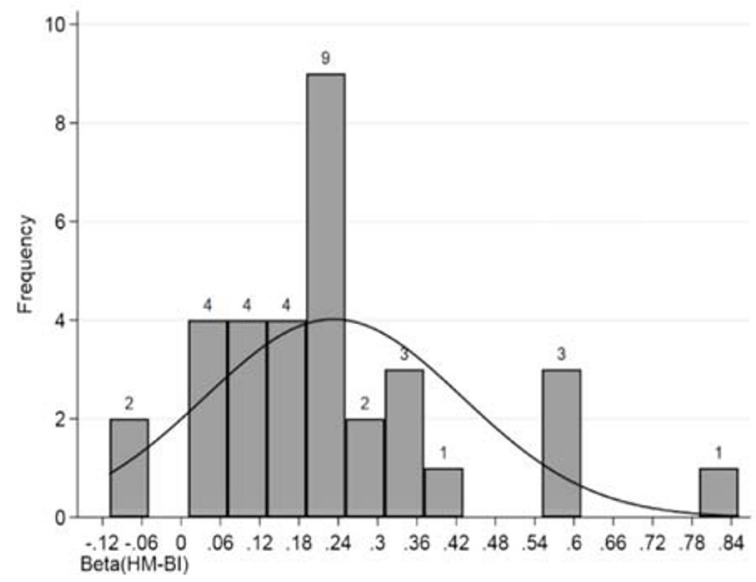

Mean: 0.233 Std. Deviation: 0.197

Minimum: -0.109 Maximum: 0.85

(e)

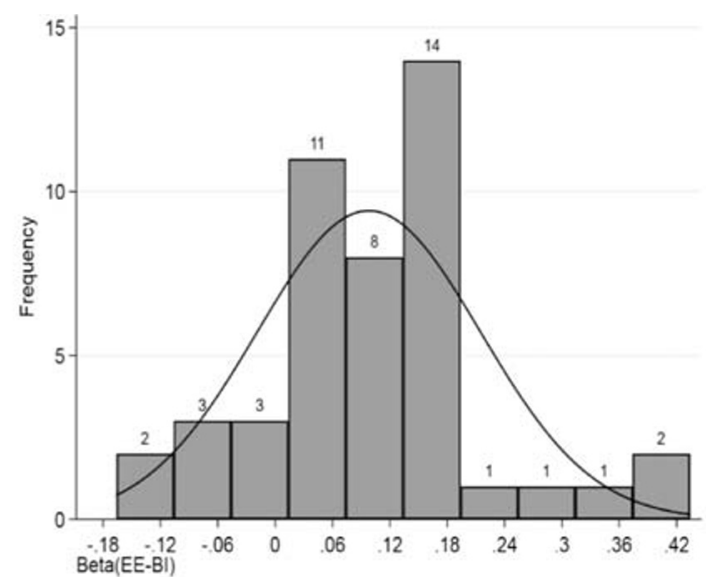

Mean: 0.098 Std. Deviation: 0.117

Minimum: -0.166 Maximum: 0.38

(b)

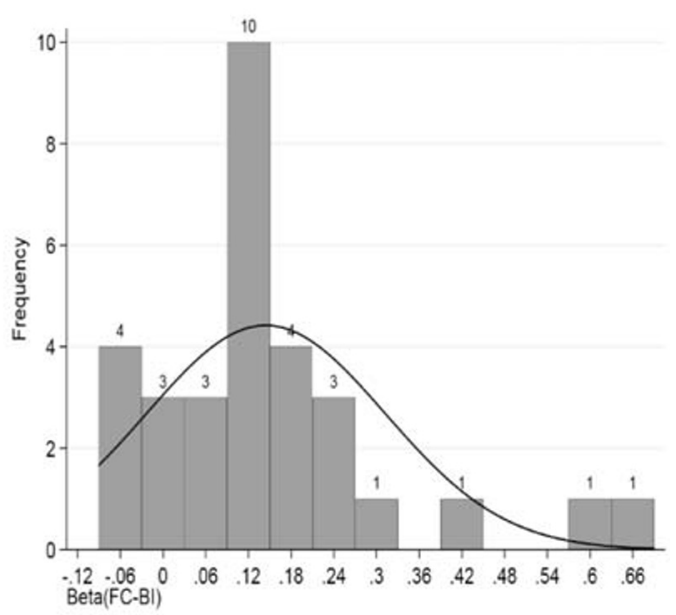

Mean: 0.144 Std. Deviation: 0.168

Minimum: -0.09 Maximum: 0.632

(d)

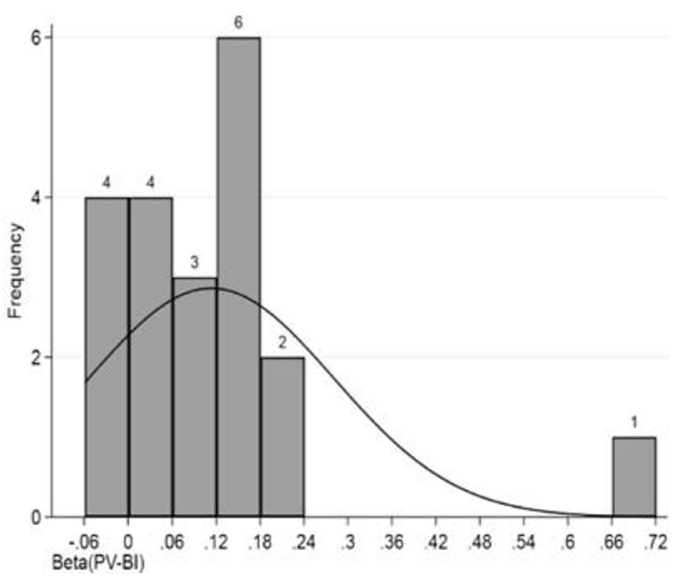

Mean: 0.113 Std. Deviation: 0.167

Minimum: -0.059 Maximum: 0.714

(f) 


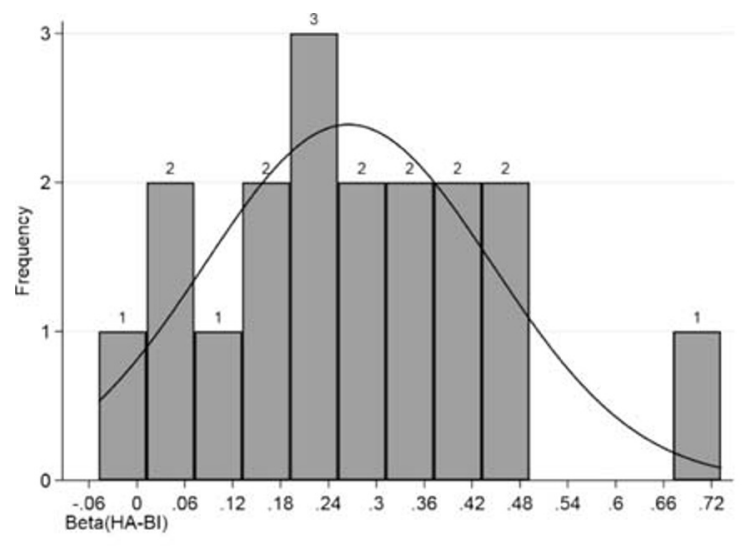

Mean: 0.265 Std. Deviation: 0.180

Minimum: -0.048 Maximum: 0.675

(g)

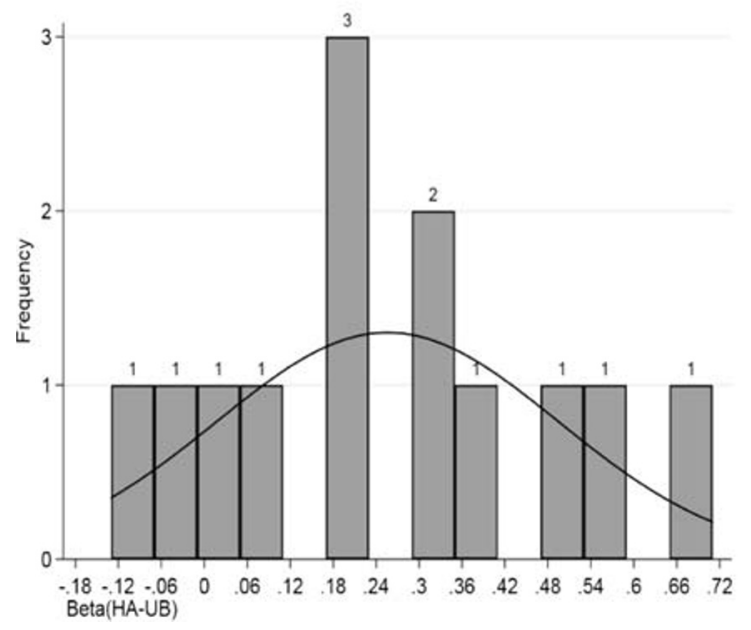

Mean: 0.256 Std. Deviation: 0.239

Minimum: -0.13 Maximum: 0.675

(i)

Fig. 4 (continued)

significantly vary from consumer to consumer depending upon their mobile devices, service providers and so on. Thus, facilitating conditions in UTAUT2 will act more like perceived behavioural control in the theory of planned behaviour (TPB) (Ajzen 1991) to influence both behavioural intention and use behaviour. To that extent, the number of studies utilizing FC $\rightarrow$ BI (31 studies) path relationship was considerably higher than those of FC $\rightarrow \mathrm{UB}$ ( 15 studies). However, 10 out 31 studies around $32 \%$ reported non-significant value for $\mathrm{FC} \rightarrow \mathrm{BI}$ and they all had effort expectancy in their model. The plausible explanation for this could be presence of effort expectancy deter facilitating conditions predicative ability on behavioural intention that needs in depth exploration (Venkatesh et al. 2003).

$\mathrm{SI} \rightarrow \mathrm{UB}$ was the third most frequently examined UTAUT2 relationship with 45 studies next only to $\mathrm{PE} \rightarrow \mathrm{BI}$ and $\mathrm{EE} \rightarrow \mathrm{BI}$.

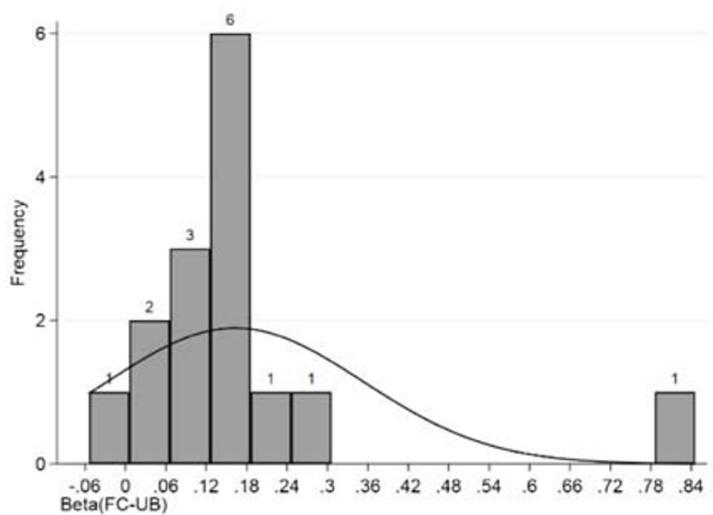

Mean: 0.163 Std. Deviation: 0.190

Minimum: -0.054 Maximum: 0.791

(h)

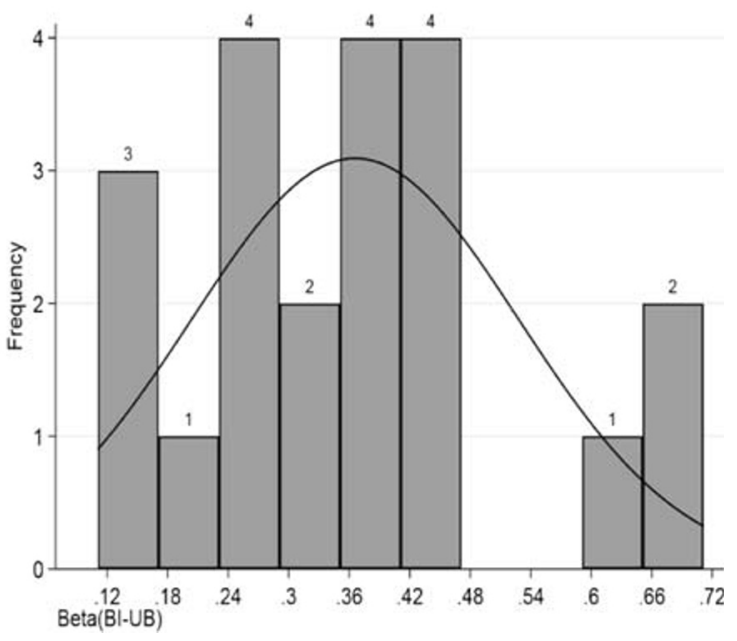

Mean: 0.366 Std. Deviation: 0.162

Minimum: 0.111 Maximum: 0.69

(j)

This path was based on assumption that individual's degree of intention to use particular technology would be determined by how important people in their life view them using those technologies (Venkatesh et al. 2003). Although majority of the studies (around 69\%) found this path as significant, they reported minimal path values. Nevertheless, the remaining $31 \%$ studies reported non-significant path values placing this path in eighth position in terms of meta-analysis $(\beta)$ strength. This indicates social influence plays significantly lesser role in influencing individual intention to use underlying technologies. The role become non-significant especially related to utilitarian technologies such as mobile banking(Alalwan et al. 2017; Baptista and Oliveira 2015).

The path $\mathrm{PV} \rightarrow \mathrm{BI}$ employed across 20 studies reported equally significant $(50 \%)$ and non-significant $(50 \%)$ results. Researchers found this path to be significant when consumers 
found their perceived benefits of using product/services completely outweighed their perceived cost of acquiring product/service (Ali et al. 2016; Tamilmani et al. 2018c). On the contrary, the path reported non-significant values when the users perceived the product/service offering examined as free of charge. Non-significant instances of PV $\rightarrow$ BI path include studies on services like "mobile banking" that offers services without special fees over other modes of financial channels (Baptista and Oliveira 2015) and products like "Smartphone" adoption in China where users can get inexpensive phones from as low as 100 USD (Gao et al. 2015b).

Finally, the path EE $\rightarrow \mathrm{BI}$, which is the second most employed UTAUT2 relationship was the weakest with 20 studies reporting non-significant values for this path most in terms of absolute number resulting in lowest meta-analysis $(\beta)$ of 0.102 . These findings are consistent with TAM (see King and He 2006) meta-analysis that revealed the path EU $\rightarrow$ BI, between perceived ease of use(PEOU), a similar construct to effort expectancy, and behavioural intention as non-significant in 30 out of 67 studies. Moreover, recent study on continued use of "perceived ease of use" in technology adoption research questions the inevitable use of the construct based on the premise that it was part of original theoretical lens adopted by researchers in this case UTAUT2. Furthermore, the study cautions the usage of effort expectancy construct in research involving existing/experienced/specialist users of technology, developed countries, and mandatory systems usage. Nevertheless, the study recommends inclusion of PEOU/EE in technology adoption research involving non/ early adopters, new technology and developing countries context (Rana et al. 2017).

\subsection{Implications for Theory and Practice}

The findings of this meta-analysis study offer several implications for research and practice alike. This study presents the cumulative findings on convergence and divergence of various path relationships in UTAUT2 model. On the one hand, researchers can observe even the best predictors such as $\mathrm{PE} \rightarrow \mathrm{BI}$ could yield non-significant results in certain context. On the other hand, the path $\mathrm{EE} \rightarrow \mathrm{BI}$ is continuously used in understanding individual technology adoption despite giving most inconsistent results. To that extent, this meta-analytic study on UTAUT2 model could serve as guideline for researchers in consumer adoption arena for selecting most appropriate constructs in their research model. For instance, the studies that reported non-significant path values for $\mathrm{HM} \rightarrow \mathrm{BI}$ focused on utilitarian value of consumer's rather than hedonic motivation. This call for researchers to be more cautions while operationalizing their constructs from existing theory/model to make necessary adaptations or omit irrelevant constructs depending upon context rather than having obligation to replicate all the constructs in underpinning model/theory. In addition, researches should be more cautious in employing effort expectancy and facilitating conditions together since presence of effort expectancy could deter facilitating conditions predictive ability on behavioural intention. Furthermore, the inclusions of moderator variables into UTAUT theories was a radical departure from then popular technology acceptance model such as TRA, TPB, and TAM. Moderators could run into the risk of being completely irrelevant in certain settings and for that reason may not be universally applicable to all context (Dwivedi et al. 2019).

Moreover, practitioners can prioritise their focus on attributes with stronger predictive strength in determining individual intention to accept and use technology. Habit emerged as strongest determinant of individual technology use. Therefore, it would be appropriate for marketers to develop interventions such as product trails enabling prospective customers to experience the products that could ultimately lead to habit development and purchase. The next two strongest predictors are performance expectancy and hedonic motivation. Hedonic motivation mostly appeals to early adopters that eventually fades out, once consumers gain experience on using product its efficiency outweighs all other attributes (Venkatesh et al. 2012). In other words, organisations can survive during early stage of product life cycle with acquisition of early adopters by offering novel product features. However, in order to thrive and capture market share they should offer compelling product during later stage of product life cycle that can efficiently improve/provide solution for the intended purpose of consumers underscoring the role of performance expectancy. As far as, facilitating conditions is concerned they can play a huge role in forming consumer's behavioural intention to use technology/product/ service. Since, facilitating conditions available to consumers may not be equal for all, organisations should take necessary interventions like providing product display in retail outlets for consumers to experience, on-line tutorials on product usage, free trail session and so on depending on the context. This effort of normalising facilitating condition across consumers will attract more prospective customers to experience the product and ultimately lead to purchase. Organisations can also leverage on other less strong factors such as the impact of social influence on consumer decision-making process by employing celebrities for advertising campaigns and reference groups to promote purchase/usage of their product/services (Chaouali et al. 2016). Finally, though the impact of price value is less significant to acquire new customers for free to use products/services, organisations should offer products/services of extra ordinary value to the customers than their perceived cost in order to price their offerings appropriately to acquire and retain consumers (Hellier et al. 2003; Ravald and Grönroos 1996). 


\subsection{Limitations and Directions for Future Research}

Researchers conducted this meta-analytic investigation in similar vein to studies (e.g., King and He 2006; Rana et al. 2015; Wu and Du 2012) to synthesise meaningful data scattered across various UTAUT2 based primary studies. Notwithstanding, the precautionary methods taken for metaanalysis in terms of coding, the interpretation of findings from this research should be interpreted in lights of some limitation. First, the studies involved for meta-analysis were limited to only two databases Web of Science and Scopus that restricted the number of empirical studies available for meta-analysis. Future, meta-analytic studies on UTAUT2 should include a large number of studies from wider range of databases to minimize publication bias for superior effect size. Second, this study was not able to conduct meta-analysis on moderating variables' effect on UTAUT2 model partly due to insufficient data reported for this relationship type. In future researchers with large pool of data should examine the variance in metaanalysis effect size of UTAUT2 model with and without its moderators such as age, gender and experience. However, the omission of moderator for meta-analysis should not undermine the results of this study based on direct effects alone rather to be viewed in the light of limitations hindering the examination of UTAUT2 model on its entirety. Third, this study found meta-analysis of path coefficients $(\beta)$ as better measure to evaluate strength of path relationships and theoretical model than average reliability and summary of zero-order correlation (r). Nevertheless, this study did not compute $\mathrm{R}^{2}$ value to explain the variance among path relationships. Future researchers should explore robust statistical method to compute $\mathrm{R}^{2}$ and could use in combination with meta-analysis of path coefficients $(\beta)$ to provide holistic view on performance of UTAUT2 theoretical model. Finally, this study restricted meta-analysis only to UTAUT2 path relationships. Future studies should include external relationships into metaanalysis to shed light on frequently used external constructs alongside with UTAUT2 and its possible theoretical adaptations. Despite these limitations, this first comprehensive metaanalysis study on UTAUT2 model provides directions for academics and practitioners alike in terms of its suitability across various contexts.

\section{Conclusion}

This study-fulfilled the objective of performing meta-analysis on UTAUT2 empirical studies through computation of mean reliability, summary of zero-order correlation, and cumulative path coefficients $(\beta)$. This meta-analysis study spanning across 60 studies involving more than 1,22,000 cumulative observations divulged large sample evidence on strength, convergence and divergence between various relationships in
UTAUT2 structural model. The noteworthy findings emerging from this research are as follows: 1) UTAUT2 moderators could not qualify for meta-analysis due to scarcity of empirical studies with moderators and their complexity paradox in interaction amongst variables; 2) Meta-analysis of path coefficients $(\beta)$ is better measure to evaluate strength of path relationships in theoretical model than average reliability and summary of zero-order correlation (r).; 3) $\mathrm{BI} \rightarrow \mathrm{UB}$ was the strongest path of all UTAUT2 relationship with all 21 studies reporting significant values emphasizing its strength; 4) $\mathrm{PE} \rightarrow \mathrm{BI}$ the most employed UTAUT2 relationship also had most significant values to emerge as one of the best predicator of consumer behavioural intention to technology acceptance in the UTAUT2 model and beyond; 5) The continuous usage of EE $\rightarrow$ BI the least strongest path of all UTAUT2 relationship is cautioned and questioned. Ironically, the path $\mathrm{EE} \rightarrow \mathrm{BI}$ was the most converging among all the path with least standard deviation and the construct EE had the highest average reliability; and 6) Behavioural Intention (BI) was the most operated endogenous variable with 37 studies followed by Use behaviour (UB) in 21 studies.

Open Access This article is licensed under a Creative Commons Attribution 4.0 International License, which permits use, sharing, adaptation, distribution and reproduction in any medium or format, as long as you give appropriate credit to the original author(s) and the source, provide a link to the Creative Commons licence, and indicate if changes were made. The images or other third party material in this article are included in the article's Creative Commons licence, unless indicated otherwise in a credit line to the material. If material is not included in the article's Creative Commons licence and your intended use is not permitted by statutory regulation or exceeds the permitted use, you will need to obtain permission directly from the copyright holder. To view a copy of this licence, visit http://creativecommons.org/licenses/by/4.0/.

\section{References}

Ain, N., Kaur, K., \& Waheed, M. (2016). The influence of learning value on learning management system use: An extension of UTAUT2. Information Development, 32(5), 1306-1321.

Ajzen, I. (1991). The theory of planned behavior. Organizational Behavior and Human Decision Processes, 50(2), 179-211.

Ajzen, I., \& Fishbein, M. (2000). Attitudes and the attitude-behavior relation: Reasoned and automatic processes. European Review of Social Psychology, 11(1), 1-33.

Alalwan, A. A., Dwivedi, Y. K., \& Rana, N. P. (2017). Factors influencing adoption of mobile banking by Jordanian bank customers: Extending UTAUT2 with trust. International Journal of Information Management, 37(3), 99-110.

Alalwan, A. A., Dwivedi, Y. K., Rana, N. P., Lal, B., \& Williams, M. D. (2015). Consumer adoption of internet banking in Jordan: Examining the role of hedonic motivation, habit, self-efficacy and trust. Journal of Financial Services Marketing, 20(2), 145-157.

Alalwan, A. A., Dwivedi, Y. K., \& Williams, M. D. (2016). Customers' intention and adoption of telebanking in Jordan. Information Systems Management, 33(2), 154-178. 
Ali, F., Nair, P. K., \& Hussain, K. (2016). An assessment of students' acceptance and usage of computer supported collaborative classrooms in hospitality and tourism schools. Journal of Hospitality, Leisure, Sport \& Tourism Education, 18, 51-60.

An, L., Han, Y., \& Tong, L. (2016). Study on the factors of online shopping intention for fresh agricultural products based on UTAUT2. Paper presented at the 2nd information technology and mechatronics engineering conference (ITOEC 2016).

Baptista, G., \& Oliveira, T. (2015). Understanding mobile banking: The unified theory of acceptance and use of technology combined with cultural moderators. Computers in Human Behavior, 50, 418-430.

Baskerville, R. L., \& Myers, M. D. (2002). Information systems as a reference discipline. MIS Quarterly, 26(1), 1-14.

Buettner, R. (2016). Getting a job via career-oriented social networking sites: The weakness of ties. In 49th annual Hawaii international conference on system sciences. Kauai, Hawaii: IEEE. https://doi. org/10.13140/RG.2.1.3249.2241.

Chaouali, W., Yahia, I. B., \& Souiden, N. (2016). The interplay of counter-conformity motivation, social influence, and trust in customers' intention to adopt internet banking services: The case of an emerging country. Journal of Retailing and Consumer Services, 28, 209-218.

Cortina, J. M. (1993). What is coefficient alpha? An examination of theory and applications. Journal of Applied Psychology, 78(1), 98104

Davis, F. D. (1989). Perceived usefulness, perceived ease of use, and user acceptance of information technology. MIS Quarterly, 13(3), 319 340

Dwivedi, Y., Khan, N., \& Papazafeiropoulou, A. (2006). Consumer adoption and usage of broadband in Bangladesh. AMCIS 2006 Proceedings, 426. Available at http://aisel.aisnet.org/amcis2006/426

Dwivedi, Y. K., Rana, N. P., Chen, H., \& Williams, M. D. (2011). A Meta-analysis of the Unified Theory of Acceptance and Use of Technology (UTAUT). In IFIP international working conference on governance and sustainability in information systems-managing the transfer and diffusion of it (pp. 155-170). Berlin, Heidelberg: Springer.

Dwivedi, Y. K., Rana, N. P., Jeyaraj, A., Clement, M., \& Williams, M. D. (2019). Re-examining the unified theory of acceptance and use of technology (UTAUT): Towards a revised theoretical model. Information Systems Frontiers, 21(3), 719-734.

Dwivedi, Y. K., Wastell, D., Laumer, S., Henriksen, H. Z., Myers, M. D., Bunker, D., Elbanna, A., Ravishankar, M. N., \& Srivastava, S. C. (2015). Research on information systems failures and successes: Status update and future directions. Information Systems Frontiers, 17(1), 143-157.

Dwivedi, Y. K., \& Williams, M. D. (2008). Demographic influence on UK citizens'e-government adoption. Electronic Government, an International Journal, 5(3), 261-274.

Eden, D. (2002). From the editors. Academy of Management Journal, $45(5), 841-846$.

Escobar-Rodríguez, T., \& Carvajal-Trujillo, E. (2013). Online drivers of consumer purchase of website airline tickets. Journal of Air Transport Management, 32, 58-64.

Escobar-Rodríguez, T., \& Carvajal-Trujillo, E. (2014). Online purchasing tickets for low cost carriers: An application of the unified theory of acceptance and use of technology (UTAUT) model. Tourism Management, 43, 70-88.

Faaeq, M. K., Ismail, N. A., Osman, W. R. S., Al-Swidi, A. K., \& Faieq, A. K. (2013). A meta-analysis of the unified theory of acceptance and use of technology studies among several countries. Electronic Government, an International Journal, 10(3-4), 343-360.

Fakhoury, R., \& Aubert, B. (2015). Citizenship, trust, and behavioural intentions to use public e-services: The case of Lebanon. International Journal of Information Management, 35(3), 346-351.
Field, A. P. (2001). Meta-analysis of correlation coefficients: A Monte Carlo comparison of fixed-and random-effects methods. Psychological Methods, 6(2), 161-180.

Gao, Y., Li, H., \& Luo, Y. (2015a). An empirical study of wearable technology acceptance in healthcare. Industrial Management \& Data Systems, 115(9), 1704-1723.

Gao, S., Yang, Y., \& Krogstie, J. (2015b). The Adoption of Smartphones Among Older Adults in China. In K. Liu, K. Nakata, W. Li, et al. (Eds.), Information and Knowledge Management in Complex Systems (p. 449). Berlin, Heidelberg: Springer.

Glass, G. V. (1976). Primary, secondary, and meta-analysis of research. Educational Researcher, 5(10), 3-8.

Gsmaintelligence. (2017). Global Mobile Trends 2017. Retrieved from https://www.gsmaintelligence.com/research/?file= 3df1b7d57b1e63a0cbc3d585feb82dc2\&download. Last accessed 06th June 2019.

Gurzki, H., \& Woisetschlaeger, D. M. (2017). Mapping the luxury research landscape: A bibliometric citation analysis. Journal of Business Research, 77, 147-166.

Hajli, N., \& Lin, X. (2016). Exploring the security of information sharing on social networking sites: The role of perceived control of information. Journal of Business Ethics, 133(1), 111-123.

Heale, R., \& Twycross, A. (2015). Validity and reliability in quantitative studies. Evidence-Based Nursing, 18(3), 66-67.

Hellier, P. K., Geursen, G. M., Carr, R. A., \& Rickard, J. A. (2003). Customer repurchase intention: A general structural equation model. European Journal of Marketing, 37(11/12), 1762-1800.

Hossain, M. A., Dwivedi, Y. K., Chan, C., Standing, C., \& Olanrewaju, A.-S. (2018). Sharing political content in online social media: A planned and unplanned behaviour approach. Information Systems Frontiers, 20(3), 485-501.

Huang, K.-Y., \& Chuang, Y.-R. (2016). A task-technology fit view of job search website impact on performance effects: An empirical analysis from Taiwan. Cogent Business \& Management, 3(1), 1253943. https://doi.org/10.1080/23311975.2016.1253943.

Hunter, J. E., \& Schmidt, F. L. (2000). Fixed effects vs. random effects meta-analysis models: Implications for cumulative research knowledge. International Journal of Selection and Assessment, 8(4), 275 292.

Hunter, J. E., Schmidt, F., \& Jackson, G. B. (1982). Meta-analysis: Cumulating research findings across studies. Beverly Hills: Sage.

Ismagilova, E., Slade, E. L., Rana, N. P., \& Dwivedi, Y. K. (2019). The effect of electronic word of mouth communications on intention to buy: A metaanalysis. Information Systems Frontiers, 1-24. https:// doi.org/10.1007/s10796-019-09924-y.

Jia, L., Hall, D., Sun, S. (2015). Trust building in consumer learning process and its effect on consumers' behavioral intention toward mobile payments. In: Proceedings of Twenty-first Americas Conference on Information Systems, Puerto Rico.

Kapoor, K. K., Dwivedi, Y. K., \& Williams, M. D. (2014). Innovation adoption attributes: A review and synthesis of research findings. European Journal of Innovation Management, 17(3), 327-348.

Kim, S. S., Malhotra, N. K., \& Narasimhan, S. (2005). Research noteTwo competing perspectives on automatic use: A theoretical and empirical comparison. Information Systems Research, 16(4), 418432.

King, W. R., \& He, J. (2005). Understanding the role and methods of meta-analysis in IS research. Communications of the Association for Information Systems, 16(1), 665-686.

King, W. R., \& He, J. (2006). A meta-analysis of the technology acceptance model. Information \& Management, 43(6), 740-755.

Kizgin, H., Jamal, A., Dey, B. L., \& Rana, N. P. (2018). The impact of social media on consumers' acculturation and purchase intentions. Information Systems Frontiers, 20(3), 503-514. 
Koenig-Lewis, N., Marquet, M., Palmer, A., \& Zhao, A. L. (2015). Enjoyment and social influence: Predicting mobile payment adoption. The Service Industries Journal, 35(10), 537-554.

Koohikamali, M., Peak, D. A., \& Prybutok, V. R. (2017). Beyond selfdisclosure: Disclosure of information about others in social network sites. Computers in Human Behavior, 69, 29-42.

Kourouthanassis, P., Boletsis, C., Bardaki, C., \& Chasanidou, D. (2015). Tourists responses to mobile augmented reality travel guides: The role of emotions on adoption behavior. Pervasive and Mobile Computing, 18, 71-87.

Lallmahomed, M. Z., Lallmahomed, N., \& Lallmahomed, G. M. (2017). Factors influencing the adoption of e-government Services in Mauritius. Telematics and Informatics, 34(4), 57-72.

Lee, Y., Kozar, K. A., \& Larsen, K. R. (2003). The technology acceptance model: Past, present, and future. Communications of the Association for Information Systems, 12(1), 752-780.

Legris, P., Ingham, J., \& Collerette, P. (2003). Why do people use information technology? A critical review of the technology acceptance model. Information \& Management, 40(3), 191-204.

Littell, J. H., Corcoran, J., \& Pillai, V. (2008). Systematic Reviews and Meta-Analysis. USA: Oxford University Press.

Ma, Q., \& Liu, L. (2004). The technology acceptance model: A metaanalysis of empirical findings. Journal of Organizational and End User Computing (JOEUC), 16(1), 59-72.

Martins, R., Oliveira, T., \& Thomas, M. A. (2016). An empirical analysis to assess the determinants of SaaS diffusion in firms. Computers in Human Behavior, 62, 19-33.

Nunnally, J. (1978). Psychometric methods. New York: McGraw-hill.

Oliveira, T., Thomas, M., Baptista, G., \& Campos, F. (2016). Mobile payment: Understanding the determinants of customer adoption and intention to recommend the technology. Computers in Human Behavior, 61, 404-414.

Ouellette, J. A., \& Wood, W. (1998). Habit and intention in everyday life: The multiple processes by which past behavior predicts future behavior. Psychological Bulletin, 124(1), 54-74.

Pfeiffer, J., Entress-Fürsteneck, M. v., Urbach, N., and Buchwald, A. 2016. Quantify-Me: Consumer Acceptance of Wearable SelfTracking Devices, in: Proceedings of the 24th European Conference on Information Systems (ECIS). Istanbul, Turkey 1-15.

Qasim, H., \& Abu-Shanab, E. (2016). Drivers of mobile payment acceptance: The impact of network externalities. Information Systems Frontiers, 18(5), 1021-1034.

Rana, N. P., Dwivedi, Y. K., Lal, B., Williams, M. D., \& Clement, M. (2017). Citizens' adoption of an electronic government system: Towards a unified view. Information Systems Frontiers, 19(3), 549-568.

Rana, N. P., Dwivedi, Y. K., \& Williams, M. D. (2013). Evaluating alternative theoretical models for examining citizen centric adoption of e-government. Transforming Government: People, Process and Policy, 7(1), 27-49.

Rana, N. P., Dwivedi, Y. K., \& Williams, M. D. (2015). A meta-analysis of existing research on citizen adoption of e-government. Information Systems Frontiers, 17(3), 547-563.

Ravald, A., \& Grönroos, C. (1996). The value concept and relationship marketing. European Journal of Marketing, 30(2), 19-30.

Sabherwal, R., Jeyaraj, A., \& Chowa, C. (2006). Information system success: Individual and organizational determinants. Management Science, 52(12), 1849-1864.

Santos, J. R. A. (1999). Cronbach's alpha: A tool for assessing the reliability of scales. Journal of Extension, 37(2), 1-5.

Schmidt, F. L. (1992). What do data really mean? Research findings, meta-analysis, and cumulative knowledge in psychology. American Psychologist, 47(10), 1173-1181.

Schmidt, F. L., \& Hunter, J. E. (2014). Methods of meta-analysis: Correcting Error and Bias in Research Findings (3nd ed.). Newbury Park: Sage Publications.
Sharma, R., \& Yetton, P. (2003). The contingent effects of management support and task interdependence on successful information systems implementation. MIS Quarterly, 27(4), 533-556.

Shaw, N. (2014). The mediating influence of trust in the adoption of the mobile wallet. Journal of Retailing and Consumer Services, 21(4), 449-459.

Slade, E., Williams, M., Dwivedi, Y., \& Piercy, N. (2015a). Exploring consumer adoption of proximity mobile payments. Journal of Strategic Marketing, 23(3), 209-223.

Slade, E. L., Dwivedi, Y. K., Piercy, N. C., \& Williams, M. D. (2015b). Modeling consumers' adoption intentions of remote mobile payments in the United Kingdom: Extending UTAUT with innovativeness, risk, and trust. Psychology \& Marketing, 32(8), 860-873.

Slade, E. L., Williams, M. D., \& Dwivedi, Y. K. (2014). Devising a research model to examine adoption of mobile payments: An extension of UTAUT2. The Marketing Review, 14(3), 310-335.

Streiner, D. L. (2003). Starting at the beginning: An introduction to coefficient alpha and internal consistency. Journal of Personality Assessment, 80(1), 99-103.

Taiwo, A. A., \& Downe, A. G. (2013). The theory of user acceptance and use of technology (UTAUT): A meta-analytic review of empirical findings. Journal of Theoretical \& Applied Information Technology, 49(1), 48-58.

Tamilmani, K., Rana, N., Prakasam, N., \& Dwivedi, Y. (2019). The battle of brain vs. heart: A literature review and meta-analysis of "hedonic motivation" use in UTAUT2. International Journal of Information Management, 46, 222-235.

Tamilmani, K., Rana, N. P., \& Dwivedi, Y. K. (2017). A systematic review of citations of UTAUT2 article and its usage trends. In A. K. Kar et al. (Eds.), I3E 2017. LNCS, vol. 10595 (pp. 38-49). Cham: Springer. https://doi.org/10.1007/978-3-319-68557-1 5.

Tamilmani, K., Rana, N. P., Alryalat, M. A. A., Al-Khowaiter, W. A., \& Dwivedi, Y. K. (2018a). Social media research in the context of emerging markets: An analysis of extant literature from information systems perspective. Journal of Advances in Management Research, 15(2), 115-129.

Tamilmani, K., Rana, N. P., \& Dwivedi, Y. K. (2018b). Use of 'Habit' is Not a Habit in Understanding Individual Technology Adoption: A Review of UTAUT2 based Empirical Studies. Paper presented at the IFIP 8.6 2018 Conference on smart working, Living and Organising, Portsmouth.

Tamilmani, K., Rana, N.P., Dwivedi, Y.K., Sahu, G.P., Roderick, S. (2018c). Exploring the role of 'Price Value' for understanding consumer adoption of technology: a review and meta-analysis of UTAUT2 based empirical studies. In Proceedings of TwentySecond Pacific Asia Conference on Information Systems, Japan.

Tavakol, M., \& Dennick, R. (2011). Making sense of Cronbach's alpha. International Journal of Medical Education, 2, 53-55.

Trang, S., \& Brendel, B. (2019). A meta-analysis of deterrence theory in information security policy compliance research. Information Systems Frontiers, 21(6), 1265-1284.

Venkatesh, V., Davis, F. D., \& Morris, M. G. (2007). Dead or alive? The development, trajectory and future of technology adoption research. Journal of the Association for Information Systems, 8(4), 267-286.

Venkatesh, V., Morris, M. G., Davis, G. B., \& Davis, F. D. (2003). User acceptance of information technology: Toward a unified view. MIS Quarterly, 27(3), 425-478.

Venkatesh, V., Thong, J. Y., \& Xu, X. (2012). Consumer acceptance and use of information technology: Extending the unified theory of acceptance and use of technology. MIS Quarterly, 36(1), 157-178.

Venkatesh, V., Thong, J. Y., \& Xu, X. (2016). Unified theory of acceptance and use of technology: A synthesis and the road ahead. Journal of the Association for Information Systems, 17(5), 328-376.

Weerakkody, V., Dwivedi, Y. K., \& Kurunananda, A. (2009). Implementing e-government in Sri Lanka: Lessons from the UK. Information Technology for Development, 15(3), 171-192. 
Weerakkody, V., Irani, Z., Kapoor, K., Sivarajah, U., \& Dwivedi, Y. K. (2017). Open data and its usability: An empirical view from the Citizen's perspective. Information Systems Frontiers, 19(2), 285300.

Williams, M. D., Dwivedi, Y. K., Lal, B., \& Schwarz, A. (2009). Contemporary trends and issues in IT adoption and diffusion research. Journal of Information Technology, 24(1), 1-10.

Williams, M. D., Rana, N. P., Dwivedi, Y. K., \& Lal, B. (2011). Is UTAUT really used or just cited for the sake of it? A systematic review of citations of UTAUT's originating article. Paper presented at the ECIS.

Wu, J., \& Du, H. (2012). Toward a better understanding of behavioral intention and system usage constructs. European Journal of Information Systems, 21(6), 680-698.

Wu, J., \& Lederer, A. (2009). A meta-analysis of the role of environmentbased voluntariness in information technology acceptance. MIS Quarterly, 33(2), 419-432.

Zhai, C., \& Huang, Y. (2016). Exploring consumers' use behavior on internet finance in China: From the perspective of the financial products similar to Yu'e Bao. Paper Presented at the 13th International Conference on Service Systems and Service Management (ICSSSM), Kunming, 1-6.

Legend: $H(r)$ : Highest (beta); L(r): Lowest (beta); Meta ( $\beta$ ): Metaanalysis path coefficient; Non-Sig $(\beta)$ : Number of non-significant path values; $p$ (ES): Estimated value of $p$ ( $p$ value); Sig $(\beta)$ : Number of significant path values; T.S.S.: Total sample size; \#: Number of studies.

Publisher's Note Springer Nature remains neutral with regard to jurisdictional claims in published maps and institutional affiliations.

Kuttimani Tamilmani is a Lecturer in Marketing, at the School of Management, Bradford University, UK. He obtained his PhD in Business Management and MBA in general management with distinction from Swansea University. Kuttimani has published and presented his research outputs in several highly regarded peer-reviewed journals and conferences such as Information systems frontiers, International Journal of Information Management, Journal of Advances in Management
Research, European Marketing Academy, and Pacific Asia conference on information systems (PACIS). His research interests are in the area of social media and online consumer behaviour. Before this, he has held various positions in the banking and financial service industry for about four years in the Middle East and India before becoming a founding member of award-winning educational start-up flintobox.com.

Nripendra P. Rana is a Professor in Digital Marketing and the Head of International Business, Marketing and Branding at the School of Management at University of Bradford, UK. His current research interests focus primarily on adoption and diffusion of emerging ICTs, e-commerce, m-commerce, e-government and digital and social media marketing. He has published more than 200 papers in a range of leading academic journals, conference proceedings, books etc. He has co-edited five books on digital and social media marketing, emerging markets and supply and operations management. He has also co-edited special issues, organised tracks, mini-tracks and panels in leading conferences. He is a Chief Editor of International Journal of Electronic Government Research and an Associate Editor of International Journal of Information Management. He is a Senior Fellow of the Higher Education Academy (SFHEA) in the UK. He is also a Visiting Scholar of Indian Institute of Management Tiruchirappalli in India.

Yogesh K. Dwivedi is a Professor of Digital Marketing and Innovation, Founding Director of the Emerging Markets Research Centre (EMaRC) and Co-Director of Research at the School of Management, Swansea University, Wales, UK. Professor Dwivedi is also currently leading the International Journal of Information Management as its Editor-in-Chief. His research interests are at the interface of Information Systems (IS) and Marketing, focusing on issues related to consumer adoption and diffusion of emerging digital innovations, digital government, and digital marketing particularly in the context of emerging markets. Professor Dwivedi has published more than 300 articles in a range of leading academic journals and conferences that are widely cited (more than 15 thousand times as per Google Scholar). Professor Dwivedi is an Associate Editor of the European Journal of Marketing, Government Information Quarterly and International Journal of Electronic Government Research, and Senior Editor of the Journal of Electronic Commerce Research. More information about Professor Dwivedi can be found at: http://www. swansea.ac.uk/staff/som/academic-staff/y.k.dwivedi/. 